\title{
CONTEXTOS MORTUORIOS EN LA CUENCA DEL RÍO RAMADILLAS (PRE-CORDILLERA DE LA REGIÓN DE ATACAMA, CHILE): DATACIONES Y ANÁLISIS DE ISÓTOPOS ESTABLES
}

\author{
MORTUARY CONTEXTS IN THE RAMADILLAS RIVER BASIN (ATACAMA \\ REGION, CHILE): RADIOCARBON DATES AND STABLE ISOTOPES ANALYSIS
}

\author{
Pablo Díaz, Aryel Pacheco ${ }^{2}$, Pilar Rivas ${ }^{3}$ y María Josefina González
}

\begin{abstract}
Se presentan los resultados de las dataciones radiocarbónicas y los análisis de isótopos estables de ${ }^{13} \mathrm{C},{ }^{15} \mathrm{~N}$ y ${ }^{18} \mathrm{O}$ de siete individuos, cuatro infantes y tres adultos, recuperados de contextos mortuorios prehispánicos de la precordillera de la Región de Atacama, Chile. Las dataciones obtenidas y los datos contextuales sugieren que los contextos mortuorios corresponderían a individuos cazadores recolectores arcaicos, del Complejo Las Ánimas, Cultura Copiapó, y de grupos Diaguita-Inca. Los análisis de dieta, en tanto, indicaron diferencias entre cazadores recolectores respecto a grupos alfareros en cuanto al consumo de vegetales; los valores $\delta^{13} \mathrm{C}$ de los primeros ocupan una posición intermedia entre el consumo de plantas $\mathrm{C}_{3}$ y $\mathrm{C}_{4}$, los últimos muestran una tendencia al mayor consumo de plantas $\mathrm{C}_{4}$. Los valores $\delta 15 \mathrm{~N}$ no mostraron diferencias importantes respecto del consumo de carne terrestre entre ambos grupos. Los valores $\delta^{18} \mathrm{O}$ sugieren que los individuos analizados tuvieron una movilidad entre ambientes similares al área donde fueron enterrados; aunque se observa un mayor enriquecimiento en los valores $\delta^{18} \mathrm{O}$ de los individuos cazadores recolectores. Estos resultados constituyen los primeros de este tipo para el área de estudio y se suman a los pocos que existen para la Región de Atacama.
\end{abstract}

Palabras claves: Dataciones radiocarbónicas, análisis isótopos estables, bioantropología, Región de Atacama.

This article presents the results of radiocarbon datings and stable isotopes analyses $\left({ }^{13} \mathrm{C},{ }^{15} \mathrm{~N}\right.$, and $\left.{ }^{18} \mathrm{O}\right)$ of seven individuals, four infants and three adults recovered from pre-Hispanic mortuary contexts in the Andean foothills of the Atacama Region (Chile). The datings obtained and contextual data suggest that the mortuary contexts correspond to archaic hunter-gatherer individuals from Las Ánimas complex, Copiapó Culture, and from Diaguita-Inca groups. Diet analysis, in turn, point to differences in vegetable consumption between hunter-gatherers and ceramic groups, since the $\delta^{13} \mathrm{C}$ values of the first group are located in an intermediate position between $C_{3}$ and $C_{4}$ plants, whereas the $\delta^{13} C$ values of the second group show a tendency to higher consumption of $C_{4}$ plants. The $\delta^{15} \mathrm{~N}$ values show no significant differences regarding terrestrial meat intake between both groups. The $\delta^{18} \mathrm{O}$ values suggest that the mobility of the individuals analyzed was circumscribed within environments similar to the area where they were buried; however, higher $\delta^{18} \mathrm{O}$ rates can be observed in the hunter-gatherer individuals. These results are the first of their type in this study area and add to the scattered existing data for the Atacama Region.

Key words: Radiocarbon dating, stable isotopes analysis, bioanthropology, Atacama Region.

Los contextos mortuorios analizados en el presente trabajo fueron hallados en el curso medio del Río Ramadillas producto de las medidas de mitigación de impacto ambiental del proyecto de explotación minera Caserones en los sitios CAS 58 y CAS 61 (Rivas 2008, 2011) (Figura 1). El Río Ramadillas está ubicado en las nacientes del Río Copiapó, área caracterizada por un relieve montañoso propio de la cordillera de la región que configura un sistema de quebradas y ríos que definen valles transversales al ir encontrándose con la Depresión Intermedia y la Cordillera de la Costa. Climáticamente, en esta región se inicia la transición desde la influencia

\footnotetext{
${ }^{1}$ Consultora Os Team Spa., Santiago, Chile. pablo.diaz.jarufe@gmail.com

${ }^{2}$ Department of Archaeology, Durham University, Durham, United Kingdom. aryel.pacheco@gmail.com

${ }^{3}$ Aswakiar Consultores, Santiago, Chile. josefa.gonzalez.andreu@gmail.com; pilarrivas.hurtado@gmail.com
} 


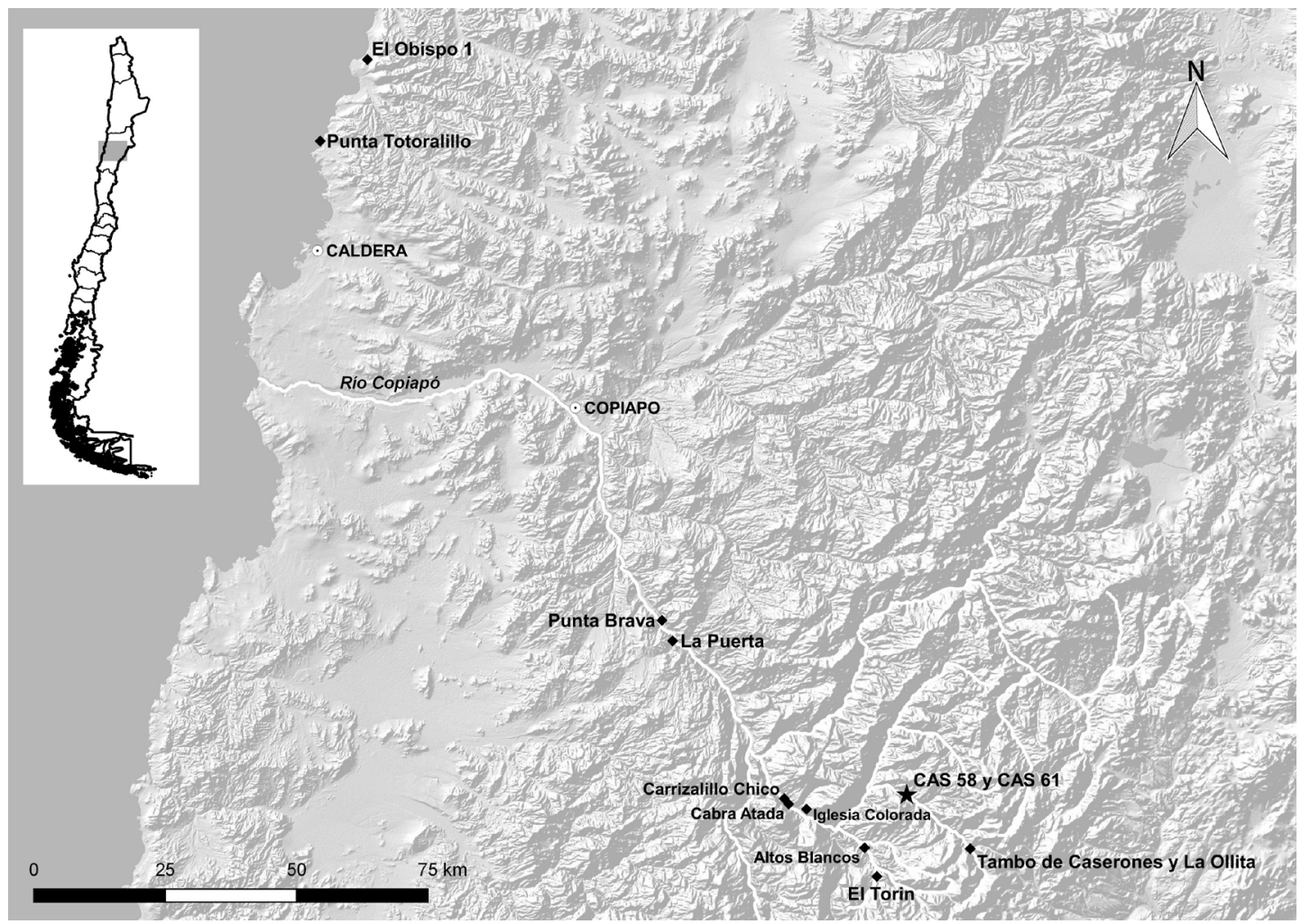

Figura 1. Ubicación de los sitios CAS 58 y CAS 61 del Proyecto Caserones y de algunos de los sitios arqueológicos mencionados de la Región de Atacama mencionados en el texto.

Location of CAS 58 and CAS 61 sites of the Caserones Project and some of the archaeological sites of the Atacama Region mentioned in the text.

subtropical del norte a un clima más templado hacia el sur (Maldonado et al. 2016). Los recursos hídricos de la zona se mantienen por un régimen de recarga hídrica pluvionival. La vegetación corresponde a la del piso andino (2.400-3.100 msm), compuesta por vegetación xerófita de matorrales bajos y algunos árboles como el algarrobo, el chañar y el pimiento boliviano (Maldonado et al. 2016; Niemeyer et al. 1991).

El sitio CAS 58 corresponde a un sitio de ocupación doméstica en el que se registraron herramientas agrícolas dispersas en superficie. El análisis cerámico dio cuenta de la presencia de elementos atribuidos a los periodos Intermedio Tardío (PIT) y Tardío (PT), mientras que los de periodos Alfarero Temprano (PAT) y Medio (PM) presentan menor frecuencia. Los camélidos constituyen la especie de mayor frecuencia en el registro de fauna, mientras que los análisis botánicos dan cuenta de la presencia de recursos vegetales como quínoa, maíz y amarantos. El sitio CAS 61 correspondía originalmente un sitio en superficie con material cerámico del PM y artefactos líticos; sin embargo, los trabajos de mantención del talud del corte del camino expusieron una serie de rasgos funerarios. Finalmente, el sitio conformó un área funeraria dividida en tres grupos de entierros diferenciados por periodos culturales: Arcaico, PM al PIT/PT, y PT. Los análisis de flora y fauna dan cuenta de la presencia de recursos y especies tales como quínoa, maíces, camélidos, aves $\mathrm{y}$ roedores.

El análisis preliminar de los materiales culturales recuperados de los contextos mortuorios de estos sitios sugiere dataciones relativas desde el periodo Arcaico al PT de la Región de Atacama. Los últimos trabajos de investigación realizados sistemáticamente en la 
Región de Atacama corresponden a la década de 1990, los que definieron los periodos para la arqueología de esta región:

\section{Periodo Arcaico (9000-100 años AC)}

Caracterizado en sitios costeros en un rango de tiempo desde el Arcaico Temprano (972-8400 AC) al Tardío (100 AC) (Cervellino 1998; Cornejo et al. 2016). Las ocupaciones más tempranas corresponden al Complejo Huentelauquén, en el sitio Obispito 1, caracterizado en el área de estudio básicamente por materiales tales como litos poligonales y puntas lanceoladas pedunculadas (Cervellino 1998). Las ocupaciones del Arcaico Medio y Tardío se asocian a grupos de pescadores especializados en a la explotación de recursos marinos, registrados en sitios como Punta Totoralillo y Puerto Maldonado (Cervellino 1998; Pacheco et al. 2013; Rivas y González 2013). El registro de contextos arqueológicos arcaicos en los valles interiores y en la precordillera de la región es escaso y sin contextos mortuorios reportados (Cervellino 1998).

\section{Periodo Alfarero Temprano (PAT, 0-850 años DC)}

Se observan innovaciones en la materialidad cultural, el paso hacia un modo de vida aldeano y la implementación de prácticas agrícolas, las cuales se aprecian en el registro de estructuras habitacionales y artefactos vinculados a la producción y procesamiento de cultígenos tales como palas líticas, morteros y manos de moler. Estas innovaciones se asocian al complejo cultural El Molle, caracterizado por el uso de cerámica monocroma pulida con decoración geométrica incisa; complejo que se ha registrado en sitios del curso medio y superior del Río Copiapó como El Torín y Carrizalillo Chico (Niemeyer 1998a; Niemeyer et al. 1989; Troncoso et al. 2016). Sus contextos mortuorios consisten en entierros de individuos en posición flectada, con escasas ofrendas cerámicas u otros artefactos, y demarcados con túmulos (Niemeyer 1998a; Niemeyer et al. 1991b).

\section{Periodo Medio (PM, 850-1200 años DC)}

Caracterizado por la aparición del complejo cultural Las Ánimas, singuralizado por su cerámica polícroma con diseños negro sobre rojo y motivos geométricos, junto con el registro de espátulas de hueso asociadas al consumo de alucinógenos, cuentas de mineral de cobre y una diversidad de artefactos elaborados en cobre o plata (Castillo 1989; Niemeyer 1998b; Troncoso et al. 2016). Sus ocupaciones se han registrado en sitios como La Puerta, Cabra Atada y Carrizalillo Grande, entre otros (Niemeyer 1998b). Sus contextos mortuorios consisten en fosas cilíndricas con cuerpos depositados en posición sedente o decúbito, asociados a vasijas cerámicas, elementos del complejo alucinógeno, collares de cuentas minerales, entre otros (Castillo 1989; Niemeyer 1998b).

\section{Periodo Intermedio Tardío (PIT, 1200-1400 años DC)}

Comprende el desarrollo de la Cultura Copiapó caracterizada a fines de la década de 1990 (Castillo 1998; Garrido 2006; Troncoso et al. 2016). Su elemento diagnóstico es la alfarería Copiapó Negro sobre Rojo con diseños de llamas estilizadas, registrada principalmente en contextos mortuorios (Garrido 2010; Troncoso et al. 2016). Su distribución abarca sitios del curso medio y alto de los ríos de la Región de Atacama, patrón que podría ser reflejo de las áreas priorizadas para su investigación (Troncoso et al. 2016). Las pocas dataciones de sus contextos se han realizado por Termoluminiscencia (Garrido 2007), a lo que se suma la escasez de contextos mortuorios registrados. El único descrito corresponde a un entierro parcialmente saqueado del sitio Altos Blancos, de forma "ampollar" y protegido por un empalizado; con un párvulo en posición semiflectada sobre una estera de totora, asociado a ofrendas cerámicas de jarros zapato, un puco Copiapó volteado con una espátula en su interior, un tubo de pluma de cóndor con boquilla de madera, y un cesto que contenía una calabaza y un pico de la misma ave. Su datación por termoluminiscencia en $1350 \pm 55$ años DC constituye uno de los primeros contextos mortuorios de esta cultura reportados como anterior a la llegada del Inca al área de estudio (Castillo 1998; Troncoso et al. 2016).

\section{Periodo Tardío (PT, 1400-1550 años DC)}

Corresponde a la entrada e influencia incaica mediatizada por grupos de la Cultura Diaguita provenientes de áreas vecinas al sur de la Región de Atacama (Castillo 1998; Gaete 1999). 
Las ocupaciones asociadas a esta expansión imperial se han datado por termoluminiscencia en la Cuenca del Río Pulido entre los 1475-1560 DC (Gaete 1999) $y$, recientemente, en el sitio Iglesia Colorada donde se han reportado dataciones entre 1400 a 1600 años DC (Garrido y Morales 2019). La Cuenca del Río Ramadillas en particular. habría sido un sector de tránsito de contingentes Diaguita-Inca para acceder a la vertiente oriental de la Cordillera de los Andes a través de los pasos cordilleranos, destacándose el Tambo de Caserones y las tamberías de las vegas de La Ollita donde se registran fragmentos cerámicos con motivos Diaguita-Inca y modelados ornitomorfos (Castillo 1998; Niemeyer et al. 1991a). Se destacan los contextos mortuorios del sitio Iglesia Colorada, caracterizados por cámaras circulares con techos de troncos y en cuyo interior se registran esqueletos en posición horizontal asociados a vasijas cerámicas de las culturas Diaguitas y Copiapó (Castillo 1998). En este sitio se destaca el registro de cabezas trofeo vinculadas a prácticas imperiales del Inca en el área (Garrido y Morales 2019).

Considerando que los periodos propuestos para la arqueología de la Región de Atacama descansan básicamente en investigaciones realizadas hace más de 20 años, el problema que se observa en este trabajo no descansa en la periodificación en sí misma, sino más bien en la falta de generación y publicación de nuevos datos que permitan complementar, acomodar o complejizar algunos aspectos de los periodos descritos, tales como sus rangos temporales o aquellos vinculados a la producción y consumo de recursos alimenticios, en virtud de la complejidad social que implica cada periodo. Debido a la reducida muestra utilizada, este trabajo se limitará a explorar cómo se comporta la relación entre las dataciones relativas de los contextos mortuorios analizados respecto a los fechados absolutos de los individuos registrados en ellos, así como la relación de la dieta de estos individuos respecto al esquema productivo propuesto para los distintos periodos culturales a los que se vinculan estos contextos.

\section{Análisis de Isótopos Estables}

Las proporciones de isótopos estables de ${ }^{13} \mathrm{C}$ $\mathrm{y}{ }^{15} \mathrm{~N}$ en los tejidos están relacionados con la dieta del organismo (Ambrose 1986; DeNiro y Epstein $1978,1981)$, mientras que la proporción del ${ }^{18} \mathrm{O}$ se relaciona con las aguas consumidas y sirve como aproximación a las áreas habitadas en función de las fuentes de agua disponibles en el entorno (Budd et al. 2001, 2004; White et al. 1998).

Los valores $\delta^{13} \mathrm{C}$ varían según la vía fotosintética de las plantas. Los de plantas $\mathrm{C}_{3}$ arrojan valores bajos del orden de $-26,5 \%$, en tanto las plantas CAM y $\mathrm{C}_{4}$ alcanzan valores más altos de aproximadamente $-12,5 \%$ o (Brown y Brown 2011). En restos humanos, los valores $\delta^{13} \mathrm{C}$ pueden medirse en la fracción orgánica del tejido óseo, el colágeno, cuya síntesis depende principalmente de los aportes proteicos de la dieta; también en la fracción inorgánica del tejido óseo, la apatita, cuya síntesis depende del plasma sanguíneo derivado del metabolismo de carbohidratos, lípidos y proteínas (Ambrose et al. 1997; Harrison y Katzenberg 2003; Tykot et al. 2009). La diferencia entre los valores $\delta^{13} \mathrm{C}$ del colágeno y la apatita permite una mejor aproximación al origen de los isótopos presentes en la dieta de un individuo (Lee-Thorp et al. 1989; Froehle et al. 2010, 2012; Kellner y Schoeninger 2007; Tykot et al. 2009).

Los valores $\delta^{15} \mathrm{~N}$ varían de acuerdo a las cadenas tróficas de los recursos consumidos, permitiendo discriminar el origen vegetal o animal de las proteínas consumidas así como su origen terrestre o marino (Schoeninger y DeNiro 1984). Al aumentar las cadenas tróficas de los recursos consumidos se produce un enriquecimiento del ${ }^{13} \mathrm{C}$ y ${ }^{15} \mathrm{~N}$ en los tejidos de los consumidores respecto su dieta, con valores entre 0 a $2 \%$ y de 3 a $5 \%$, respectivamente (Bocherens y Drucker 2003). Este enriquecimiento también ocurre en lactantes alimentados con leche materna, con valores de $1 \%$ y de 2 a $3 \%$ en el $\delta^{13} \mathrm{C}$ y $\delta^{15} \mathrm{~N}$, respectivamente (Fogel et al. 1989; Fuller et al. 2006; Smith et al. 2017; Tsutaya y Yoneda 2013, 2015).

Los valores $\delta^{18} \mathrm{O}$ se vinculan al consumo de recursos hídricos que, al depender de la ubicación geográfica de las fuentes de agua consumidas, permiten una aproximación a las áreas habitadas por el consumidor. El ${ }^{18} \mathrm{O}$ de las aguas disminuye en relación a la mayor distancia de las fuentes de agua respecto al mar y al aumento de la altitud; también disminuye con el aumento de la latitud (Brown y Brown 2011; Knudson 2009). Los valores $\delta^{18} \mathrm{O}$ medidos en muestras de tejido óseo y agua se calculan en relación a los estándares vPDB y vSMOW, respectivamente. Para compararlos, es necesario calibrar los valores 
$\delta^{18} \mathrm{O}_{\text {vPDB }}$ con distintas ecuaciones que permiten expresarlos en valores $\delta^{18} \mathrm{O}_{\text {vsmow }}$ y así cotejarlos con las aguas regionales. Una de las ventajas que tiene esta aproximación a la movilidad, particularmente en el área de estudio, descansa en la distancia que existe entre la línea de costa y las altas cumbres de la Cordillera de los Andes, que no supera los 260 $\mathrm{km}$. Si bien los isótopos de oxígeno no proveen una señal exacta para establecer el origen regional de un individuo, como si lo podría realizar el estudio de los isótopos de estroncio (Knudson 2009), la variación que experimenta la señal isotópica en función de la topografía del área y su distancia al mar permitiría una aproximación al origen de estos individuos distinguiendo áreas de costa, valles interiores y cordillera (Sanhueza y Falabella 2010).

El ${ }^{18} \mathrm{O}$ permitiría también distinguir el proceso de destete de infantes, ya que durante el proceso fisiológico de producción de leche se daría un enriquecimiento de este isótopo respecto a las aguas consumidas, el cual se vería reflejado en los tejidos del infante durante su periodo de lactancia (Bryant y Froelich 1995; Kohn et al. 1996; Wright y Schwarcz 1998). La diferencia entre los valores $\delta^{18} \mathrm{O}$ de infantes amamantados respecto a los adultos sería de aproximadamente $+1 \%$ o (Britton et al. 2015; Wright y Schwarcz 1998).

Dada la falta de estudios sistemáticos de isótopos estables en la Región de Atacama, se hace necesario consultar aquellos realizados en áreas vecinas y con procesos culturales similares a los de esta región. Es por esto que se considera como marco de referencia los estudios realizados en la Región de Coquimbo y el área de Chile central, porque los periodos arqueológicos definidos para estas áreas guardan similitudes con el área de estudio en cuanto a tiempos y procesos culturales, especialmente a partir del PAT (Falabella et al. 2016; Troncoso et al. 2016). En general, en estos trabajos se ha sugerido que la dieta de las poblaciones arcaicas descansaba principalmente en el consumo de recursos vegetales $\mathrm{C}_{3}$ y camélidos, observándose cambios hacia fines del periodo Arcaico Tardío según lo indican los valores bajos del $\delta^{15} \mathrm{~N}$ que sugieren un menor consumo de camélidos (Gómez y Pacheco 2016; Sanhueza y Falabella 2010). Durante el PAT se observa la aparición de restos de maíz en distintos contextos arqueológicos, pero sin observarse su consumo significativo de acuerdo a los valores bajos del $\delta^{13} \mathrm{C}$ (Alfonso-Durruty et al. 2017; Falabella et al. 2008). La mayor incorporación de recursos vegetales $C_{4}$ a la dieta de estas poblaciones podría estar ocurriendo durante el PIT, donde se observan valores más altos del $\delta^{13} \mathrm{C}$, los cuales disminuyen ligeramente al momento en que estas poblaciones empiezan a entrar en la esfera de influencia del imperio Inca (Alfonso-Durruty et al. 2017; Falabella et al. 2007, 2008).

\section{Materiales y Métodos}

\section{Los contextos mortuorios de la muestra}

Las labores de monitoreo y rescate arqueológico en el marco del Proyecto Caserones recuperaron un total de 29 individuos en la ribera sur del Río Ramadillas. Se seleccionó una muestra de cuatro infantes y tres adultos provenientes de siete contextos mortuorios registrados en los sitios CAS 58 y CAS 61 (Tabla 1). Esta selección se basó en criterios antropológicos (esqueletos mejor preservados y/o mayormente representados) y arqueológicos (contextos mortuorios con materiales culturales diagnósticos asociados, hallados en sitios arqueológicos propiamente tales y no como hallazgos aislados). La edad de los individuos infantes fue estimada de acuerdo al desarrollo y erupción de las piezas dentales deciduas y permanentes (Gustafson y Koch 1974; Buikstra y Ubelaker 1994). La edad de los individuos adultos se estimó a partir de la morfología de la sínfisis púbica y superficie auricular de los coxales, la morfología de la terminación esternal de las costillas, y según el estado de fusión de suturas craneales (Buikstra y Ubelaker 1994).

Los individuos fueron recuperados de contextos mortuorios de distintas características. El individuo E15 del sitio CAS 58 corresponde a un infante de aproximadamente 18 meses de edad registrado en un entierro primario y simple, asociado a un fogón debajo del individuo. En el fogón se encontraban tres puntas de proyectil de factura arcaica (Figura 2) y dos piedras redondeadas y grandes.

El individuo E4 del sitio CAS 61 corresponde a un adulto que yacía en un entierro primario y simple. Asociado al entierro se registró a un fogón ubicado en la capa de relleno de la fosa superior al cuerpo, con bloques de piedras dispuestos bajo y sobre el esqueleto junto al cual se registró un cuchillo lítico. En los dos contextos mortuorios hasta aquí descritos no hay registro de material cerámico.

El individuo E5 del sitio CAS 61 corresponde a un adulto hallado en un entierro primario y simple. Aunque 


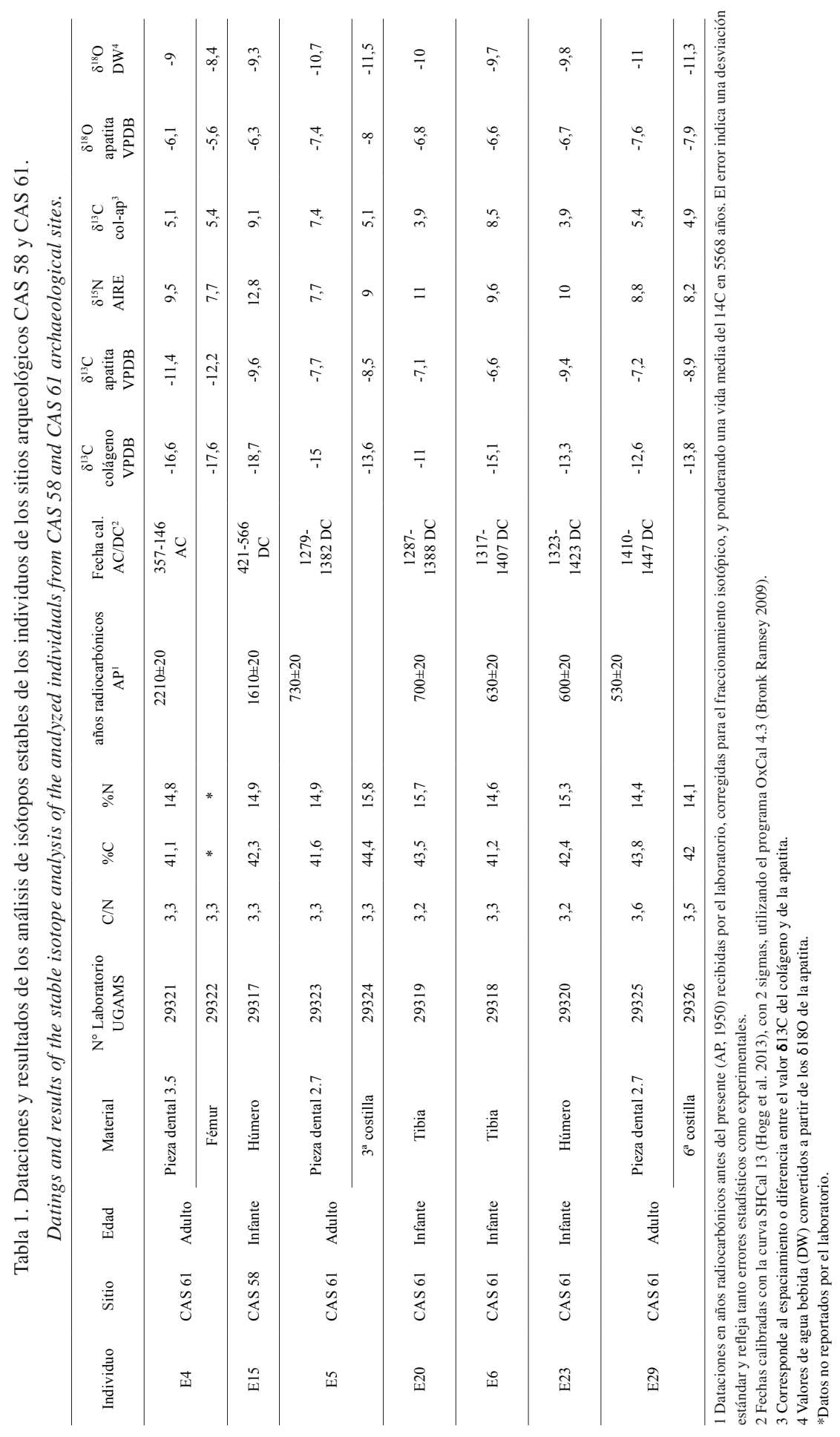



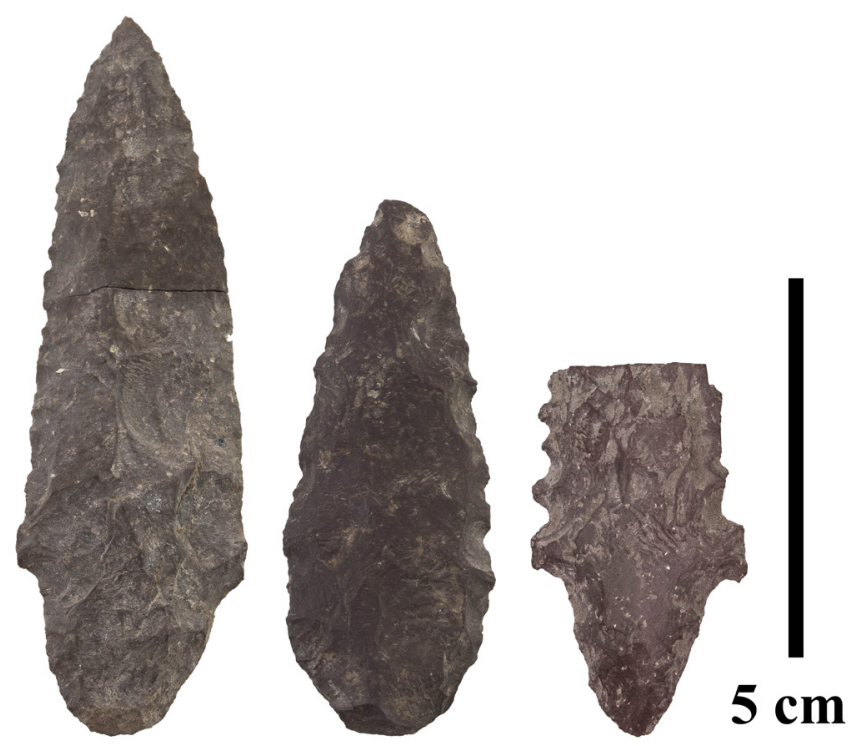

Figura 2. Puntas de proyectil arcaicas registradas en el contexto mortuorio del individuo E15, sitio CAS 58.

Archaic projectile points recorded in the mortuary context of individual E15, CAS 58 site.

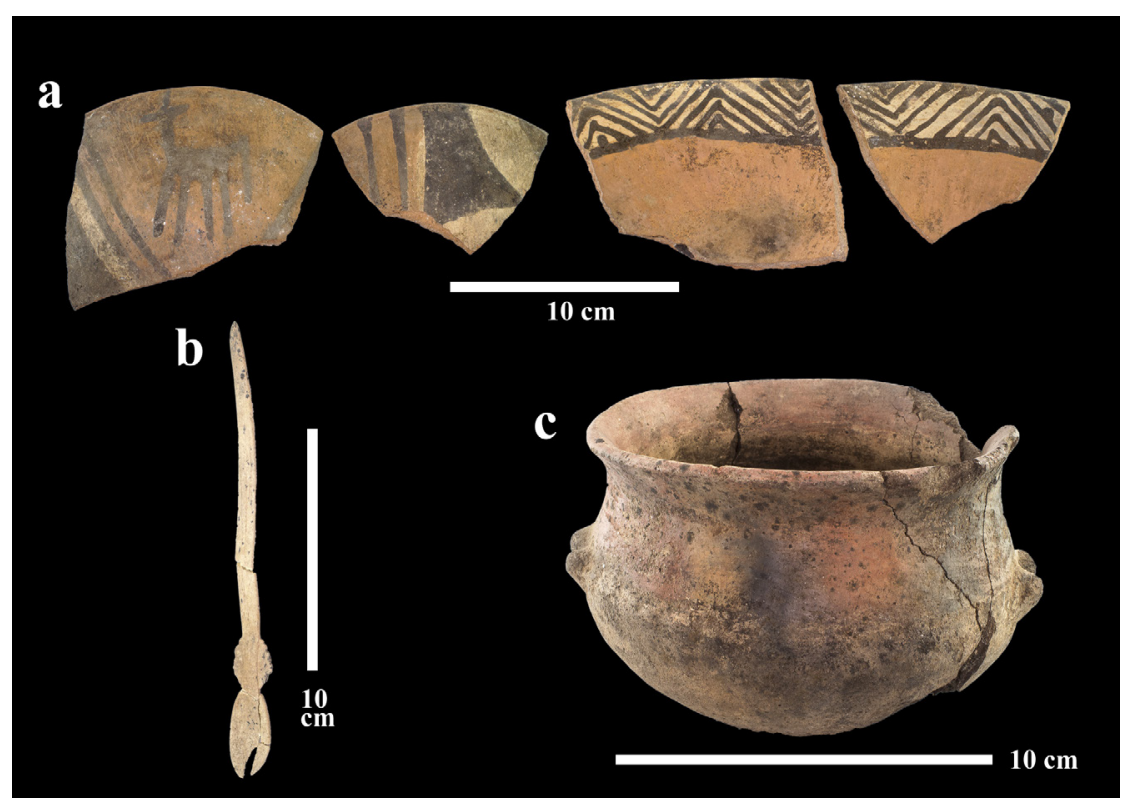

Figura 3. Material cerámico Ánimas (a) y espátula de hueso (b) registrados en el contexto mortuorio del individuo E5, sitio CAS 61. Vasija cerámica (c), posiblemente Ánimas, registrada en el contexto mortuorio del individuo E20, sitio CAS 61.

Ceramic material Ánimas (a) and bone spatula (b) recorded in the mortuary context of individual E5, CAS 61 site. Ceramic vessel (c), possibly Ánimas, recorded in the mortuary context of individual E20, CAS 61 site. 


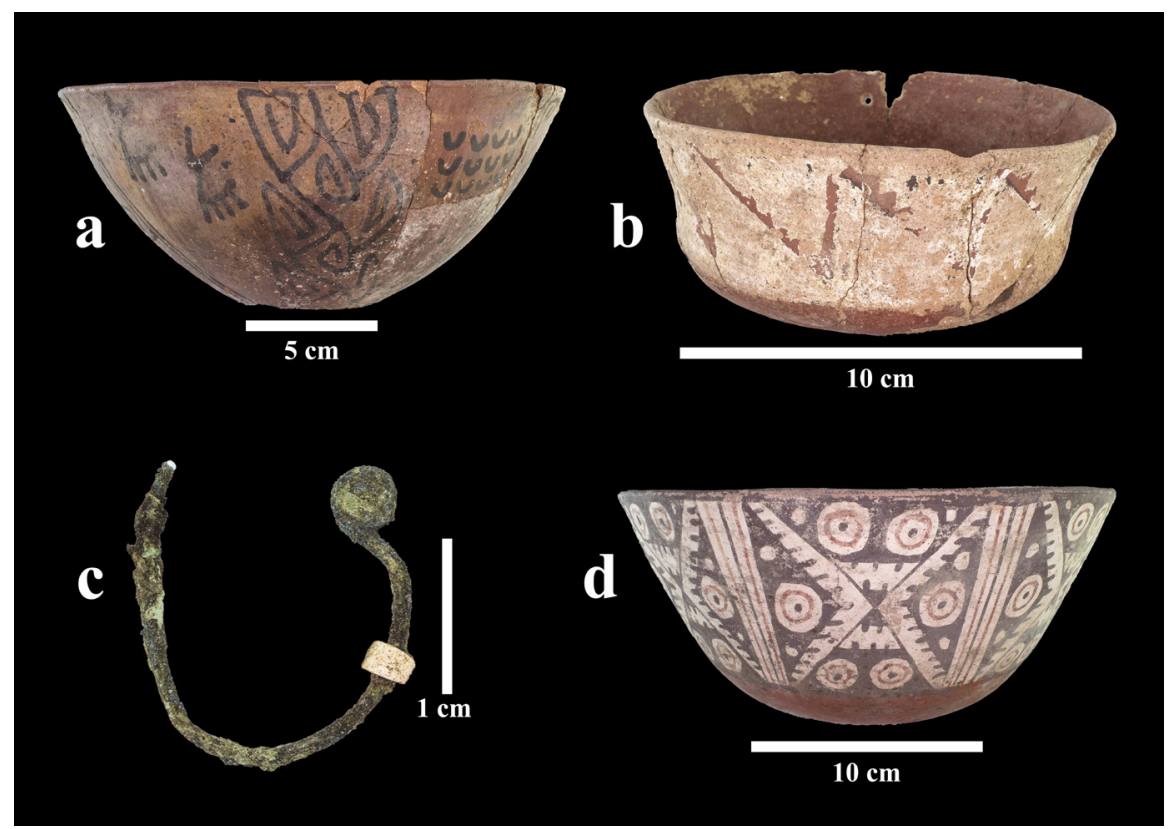

Figura 4. Cerámica decorada de la culturas Copiapó (a) y Diaguita-Inca (b) registradas en el contexto mortuorio de los individuos E23 y E24, sitio CAS 61. Aro de cobre compuesto (c) y vasija cerámica Diaguita-Inca registrados en el contexto mortuorio del individuo E29, sitio CAS 61.

Decorated ceramics from the Copiapó (a) and Diaguita-Inca $(b)$ cultures recorded in the mortuary context of individuals E23 and E24, CAS 61 site. Composite copper earring (c) and Diaguita-Inca ceramic vessel recorded in the mortuary context of individual E29, CAS 61 site.

el contexto original fue intervenido por maquinaria pesada, se pudo recuperar un posible jarro zapato fragmentado, fragmentos de una vasija cerámica tipo Ánimas diagnóstica del PM, y una espátula de hueso fragmentada y casi completa (Figuras 3 a y $3 b$ ).

El individuo E20 del sitio CAS 61 corresponde a un infante de aproximadamente 18 meses de edad, hallado en un entierro primario y en asociación a una vasija cerámica monocroma con cuatro mamelones, posiblemente Ánimas (Figura 3c).

El contexto mortuorio del individuo E6 del sitio CAS 61 consiste en el entierro primario de un infante de 4 a 6 meses de edad, asociado a un puco decorado negro sobre rojo diagnóstico de la Cultura Copiapó del PIT (Figura 4a); en el interior de este puco había una pequeña vasija monocroma globular, con cuello y asa. El esqueleto se encontró depositado sobre un rasgo de matriz orgánica, de forma circular, en la que se registraron maderas y fragmentos de marlos de maíz.

El contexto mortuorio de los individuos E23 y E24 corresponde al entierro primario de dos infantes de 18 y tres meses de edad, respectivamente. Sobre la pelvis del individuo E23, y próxima a los pies del individuo E24, se encontró una vasija tipo Copiapó Negro sobre Rojo. Sobre el hombro izquierdo del individuo E23 se halló una tortera de hueso con decoraciones incisas de figuras antropomorfas; y a nivel del cráneo se registró un puco color salmón con decoraciones en color blanco sobre rojo, posiblemente Diaguita-Inca con notorias marcas de uso (Figura 4b). Inmediatamente sobre el puco se encontraron restos de cestería de forma circular. La vasija registrada en el contexto es diagnóstica de la Cultura Copiapó del PIT, mientras el puco sería posiblemente del estilo Diaguita-Inca.

El contexto del individuo E29 consiste en el entierro primario de un adulto. En un costado del cráneo se registró un aro circular de cobre con una cuenta de piedra de color blanco introducida en él, formando una pieza compuesta (Figura 4c). También, junto al cráneo, se recuperaron dos vasijas cerámicas, la primera corresponde a un puco polícromo con decoración Diaguita-Inca diagnóstica (Figura 4d), y la segunda es un jarro zapato monocromo. Bajo la vasija polícroma se descubrió una tortera de hueso 
con extremos aguzados y entre las dos vasijas se descubrieron restos de cestería en muy mal estado de conservación.

\section{Muestras y análisis realizados}

Para cada uno de los cuatro infantes se tomó una muestra de los huesos largos de sus extremidades para datación y análisis de isótopos estables; en cambio, se tomaron dos muestras para cada uno de los tres adultos: una dental, para datación y análisis de isotopos estables, y otra de huesos largos o costillas para análisis de isótopos estables. De acuerdo a las edades de formación de las piezas dentales muestreadas en los tres adultos (Tabla 1), estas permitirían aproximarnos a la dieta durante la niñez de estos individuos. Todas las muestras fueron registradas fotográficamente, y de las muestras dentales se hicieron réplicas $3 \mathrm{D}$ mediante fotogrametría.

Las dataciones radiocarbónicas y los análisis de isótopos estables fueron realizados en el Center for Applied Isotope Studies (CAIS) de la Universidad de Georgia, Estados Unidos, de acuerdo a la metodología descrita por Cherkinsky et al. (2010): Las muestras fueron tratadas con ácido acético $(1 \mathrm{~N}, 1 \mathrm{~mol}$ por litro) para eliminar carbonatos superficiales y secundarios. Luego, se hicieron reaccionar con $\mathrm{HCl}(1 \mathrm{~N}, 1$ mol por litro) para disolver el mineral óseo y liberar el dióxido de carbono de la bioapatita. Los residuos fueron filtrados, enjuagados con agua desionizada y calentados a $80^{\circ} \mathrm{C}$ bajo condiciones ligeramente ácidas $(\mathrm{pH}=3)$ durante 6 horas. El colágeno seco fue quemado a $575^{\circ} \mathrm{C}$ en presencia de $\mathrm{CuO}$, separándose criogénicamente el dióxido de carbono y el nitrógeno. Para análisis de radiocarbono, el dióxido de carbono se convirtió catalíticamente en grafito usando el método de Vogel et al. (1984). Las proporciones ${ }^{14} \mathrm{C} /{ }^{13} \mathrm{C}$ del grafito se midieron usando el espectrómetro acelerador de masas CAIS 0.5 MeV. Para los análisis de isótopos estables, las proporciones isotópicas ${ }^{13} \mathrm{C} /{ }^{12} \mathrm{C}$ y ${ }^{15} \mathrm{~N} /{ }^{14} \mathrm{~N}$ se midieron separadamente con un espectrómetro de masa de proporciones isotópicas Finnigan MAT 252. La calibración se hizo utilizando aceite de hidrocarburo estándar NIST y NBS-22 (Noakes et al. 2006). Las relaciones se midieron respecto al estándar VPDB (Vienna Pee Dee Belemnite) para el valor $\delta^{13} \mathrm{C}$ del colágeno, y al nitrógeno atmosférico del aire (AIR) para el valor $\delta^{15} \mathrm{~N}$ (Schwarcz y Schoeninger 2011). El error fue menor al 0,1 y $0,2 \%$ para los valores $\delta^{13} \mathrm{C}$ y $\delta^{15} \mathrm{~N}$, respectivamente.

Las dataciones obtenidas fueron convertidas a fechas calendáricas con un intervalo de confianza de $95 \%$ utilizando el programa OxCal v4.3 (Bronk Ramsey 2009) y la curva de calibración SHCal13 (Hogg et al. 2013). Los resultados de los análisis de isótopos estables fueron analizados estadísticamente. Debido al reducido tamaño muestral, los datos fueron analizados conservadoramente con la prueba Kruskal-Wallis definiéndose grupos para la categoría "edad" en infante ( 0 a 3 años), niño (3 a 12 años) y adulto (mayor de 20 años), siendo estas últimas dos categorías exclusivas de los individuos adultos ya que cuentan con una muestra dental que refleja la dieta durante las edades de formación de la pieza dental en la niñez, y otra de cortical ósea, que refleja la dieta en los años previos a la muerte del individuo. También se agruparon las muestras según su rango cronológico, pre 600 cal. DC y post 1200 cal. DC de acuerdo al resultado de las dataciones, con el objetivo de apreciar si hay una tendencia temporal de los resultados.

Dada la falta de antecedentes para los valores isotópicos de los recursos de flora y fauna de la región de estudio, los valores $\delta^{13} \mathrm{C}$ y $\delta^{15} \mathrm{~N}$ obtenidos de los individuos analizados fueron comparados con valores isotópicos de recursos de flora y fauna del norte grande de Chile (Tieszen y Chapman 1992) corregidos con un factor de $+1,9 \%$ para el efecto Suess (Santana et al. 2015) y un factor $+1 \mathrm{y}+3 \%$ o para los valores $\delta^{13} \mathrm{C}$ y $\delta^{15} \mathrm{~N}$, respectivamente, como aproximación conservadora para al factor de discriminación trófica.

Esta comparación fue complementada con el modelo multivariado de reconstrucción de dietas prehispánicas propuesto por Froehle et al. (2012), quienes utilizan los valores $\delta^{15} \mathrm{~N}$ y $\delta^{13} \mathrm{C}$ del colágeno y apatita $\left(\delta^{13} \mathrm{C}_{\mathrm{col}}\right.$ y $\left.\delta^{13} \mathrm{C}_{\mathrm{ap}}\right)$ para distinguir entre cinco grupos de dieta definidos a partir de estudios experimentales en modelos animales y muestras bioantropológicas de poblaciones arqueológicas bien documentadas (Froehle et al. 2010, 2012): Grupo 1 (100\% dieta general y proteína $\mathrm{C}_{3}$ ), Grupo 2 (razón 30:70\% dieta general $\mathrm{C}_{3}: \mathrm{C}_{4},>50 \%$ proteína $\mathrm{C}_{4}$ ), Grupo 
Tabla 2. Muestras bioantropológicas de la Región de Coquimbo y Chile central con datos de isótopos estables publicados. Bioanthropological samples from the Coquimbo Region and central Chile with stable isotope data published.

\begin{tabular}{|c|c|c|c|c|c|c|c|c|c|}
\hline \multirow[t]{2}{*}{ Área } & \multirow{2}{*}{\multicolumn{2}{|c|}{ Periodo }} & \multirow{2}{*}{$\begin{array}{c}\text { Datación/Fecha } \\
\bar{X}\end{array}$} & \multicolumn{2}{|c|}{$\delta^{13} \mathrm{C}$ colágeno VPDB } & \multicolumn{2}{|c|}{$\begin{array}{c}\delta^{15} \mathrm{~N} \\
\text { AIRE }\end{array}$} & \multirow[t]{2}{*}{$\mathrm{n}$} & \multirow{2}{*}{ Referencia } \\
\hline & & & & SD & $\overline{\mathrm{X}}$ & $\mathrm{SD}$ & & & \\
\hline \multirow{4}{*}{$\begin{array}{l}\text { Norte } \\
\text { semiárido }\end{array}$} & \multicolumn{2}{|c|}{ Arcaico Tardío } & $\begin{array}{c}2440-1890 \pm 25 \\
\mathrm{AP}^{1}\end{array}$ & $-17,6$ & 2,2 & 9,7 & 1,5 & 7 & \multirow{4}{*}{ Becker et al. 2015} \\
\hline & \multicolumn{2}{|c|}{ Alfarero Temprano } & $0-850 \mathrm{DC}$ & $-15,6$ & 0,5 & 6,6 & 0,2 & 5 & \\
\hline & \multicolumn{2}{|c|}{ Intermedio Tardío } & $490-410 \pm 25 \mathrm{AP}^{1}$ & $-12,1$ & 2,3 & 7,4 & 1,3 & 9 & \\
\hline & \multicolumn{2}{|c|}{ Tardío } & datación relativa $^{2}$ & $-12,9$ & 0,9 & 9,2 & 0,9 & 15 & \\
\hline \multirow{2}{*}{$\begin{array}{l}\text { Valle } \\
\text { Mauro }\end{array}$} & \multicolumn{2}{|c|}{ Arcaico Tardío } & $1300-87 \mathrm{AC}$ & -21 & 1,1 & 7,6 & 1,9 & 14 & \multirow{2}{*}{$\begin{array}{c}\text { Gómez y Pacheco } \\
2016\end{array}$} \\
\hline & \multicolumn{2}{|c|}{ Alfarero Temprano } & $230-934 \mathrm{DC}$ & $-18,8$ & 0,9 & 5,4 & 0,8 & 12 & \\
\hline \multirow{5}{*}{$\begin{array}{l}\text { Chile } \\
\text { central }\end{array}$} & \multicolumn{2}{|c|}{ Arcaico } & $5000-2500 \mathrm{AC}$ & $-18,6$ & 0,9 & 10,7 & 2,6 & 5 & \multirow{5}{*}{$\begin{array}{l}\text { Sanhueza y Falabella } \\
2010 \\
\text { Falabella et al. } 2007\end{array}$} \\
\hline & \multirow{2}{*}{$\begin{array}{l}\text { Alfarero } \\
\text { Temprano }\end{array}$} & Bato & \multirow{2}{*}{$550-1250 \mathrm{DC}$} & $-18,4$ & 1,9 & 6,1 & 0,4 & 2 & \\
\hline & & Llolleo & & $-13,5$ & 0,7 & 6 & 0,8 & 10 & \\
\hline & \multicolumn{2}{|c|}{$\begin{array}{l}\text { Intermedio Tardío } \\
\text { (Aconcagua) }\end{array}$} & $975-1440$ DC & $-11,6$ & 0,8 & 6,8 & 1 & 17 & \\
\hline & \multicolumn{2}{|c|}{ Tardío (Inka) } & $1470-1495$ DC & $-13,1$ & 1,2 & 5,9 & 1 & 15 & \\
\hline
\end{tabular}

3 (razón 50:50\% dieta general $\mathrm{C}_{3}: \mathrm{C}_{4}$, proteína marina), Grupo 4 (razón 70:30\% dieta general $\mathrm{C}_{3}: \mathrm{C}_{4}, \geq 65 \%$ proteína $\mathrm{C}_{3}$ ) y el Grupo 5 (razón $30: 70 \%$ dieta general $\mathrm{C}_{3}: \mathrm{C}_{4}, \geq 65 \%$ proteína $\mathrm{C}_{3}$ ). A partir estos grupos y mediante el análisis discriminante de estos, el modelo ofrece dos funciones matemáticas que permiten ubicar cada individuo en cualquiera de los grupos de dieta ya mencionados (Froehle et al. 2012).También se realizaron comparaciones con valores $\delta^{13} \mathrm{C}$ y $\delta^{15} \mathrm{~N}$ reportados en muestras bioantropológicas de los valles interiores de la Región de Coquimbo (Becker et al. 2015; Gómez y Pacheco 2016) y Chile Central (Falabella et al. 2007; Sanhueza y Falabella 2010) (Tabla 2). Esta comparación permite explorar similitudes o diferencias entre los componentes de la dieta de los individuos analizados respecto muestras bioantropológicas asociadas procesos culturales descritos en regiones vecinas al área de estudio y que cuentan con estudios más sistemáticos en los últimos años.

Finalmente, los valores $\delta^{18} \mathrm{O}_{\mathrm{vPDB}}$ obtenidos de las muestras dentales y de la apatita fueron convertidos en valores $\delta^{18} \mathrm{O}_{\mathrm{DW}}$ (agua consumida) utilizando las fórmulas de Coplen (1988:295, ecuación 11) y las fórmulas combinadas de Daux y et al. (2008:1143, ecuación 6) y Chenery et al. $\left(2012, \delta^{18} \mathrm{O}_{\mathrm{P}}=1,0322\right.$ x $\left.\delta^{18} O_{C}-9,6848\right)$. Estos valores $\delta^{18} O_{D W}$ fueron comparados con valores $\delta^{18} \mathrm{O}_{\text {vSMOw }}$ registrados en muestras de aguas superficiales (Schlumberger Water Services 2008; Troncoso et al. 2012) y aguas lluvias de la Cuenca del Río Copiapó (Lorca 2011) (Tabla 3) para ponderar posibles eventos de movilidad costa-interior en los individuos que componen la muestra.

En estos análisis la muestra incluye cuatro individuos infantes. Los estudios de isótopos realizados en Chile central han considerado individuos subadultos y adultos, mientras que los de la Región de Coquimbo han incluido lactantes e infantes (Gómez y Pacheco 2016) o bien han omitido reportar la edad (Becker et al. 2015). Si bien nuestra muestra incluye infantes en los análisis y comparaciones, se considera el efecto de los factores de enriquecimiento trófico que se pueda observar en los valores isotópicos de estos y sus alcances en la interpretación de los datos.

\section{Resultados}

La Tabla 1 identifica los individuos analizados, las dataciones obtenidas y su calibración en fechas calendáricas, los valores isotópicos de las muestras y la conversión de los valores $\delta^{18} \mathrm{O}_{\text {vPDB }}$ de la apatita en valores $\delta^{18} \mathrm{O}_{\mathrm{DW}}$. Los valores de la proporción de $\mathrm{C} / \mathrm{N}$ de las muestras están dentro del rango de 2,9 a 


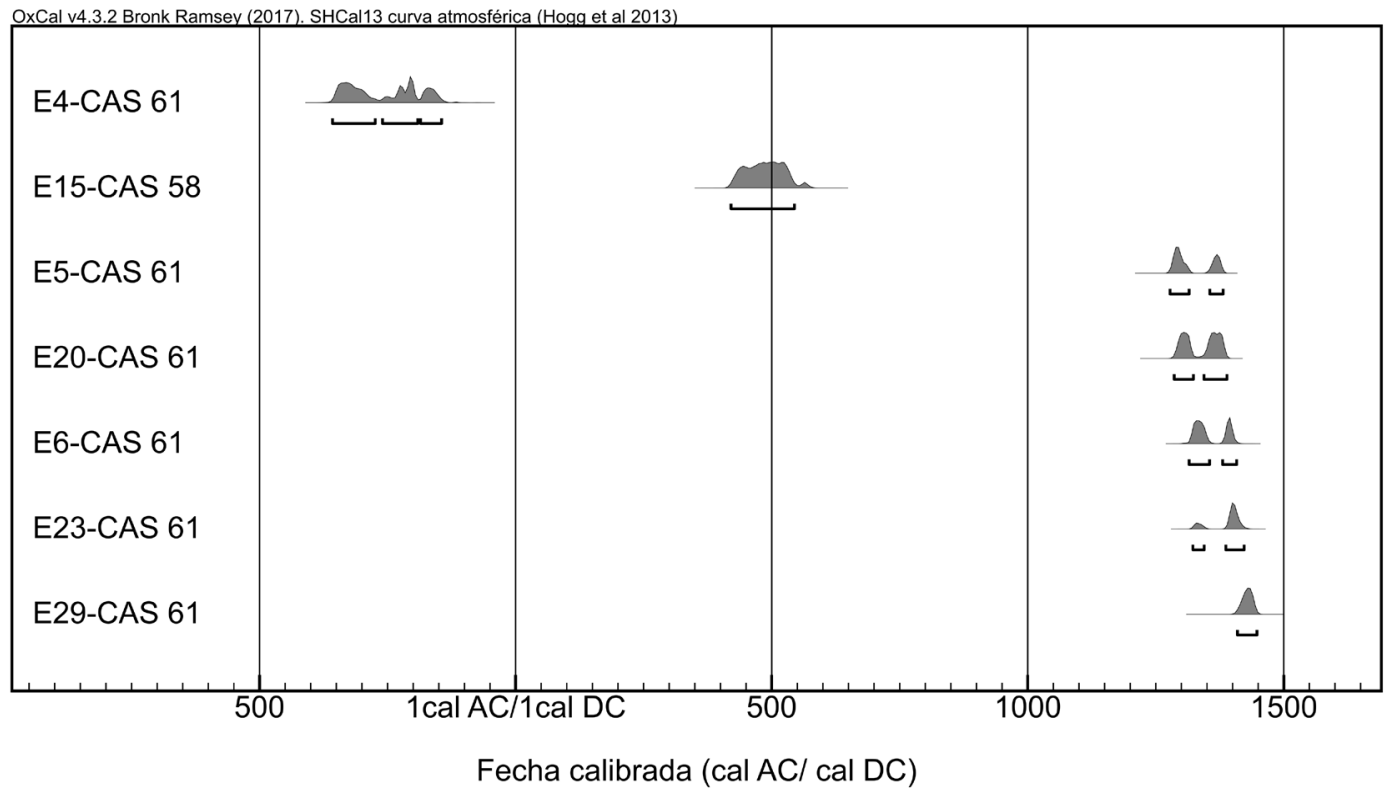

Figura 5. Fechas calibradas de los contextos funerarios muestreados del Proyecto Caserones.

Calibrated dates of the burial contexts sampled in the Caserones Project.

3,6 que, sumado a los $\% \mathrm{Cy} \% \mathrm{~N}$ observados, indican la óptima conservación del colágeno analizado (Ambrose 1990; DeNiro 1985; van Klinken 1999). Solo en una muestra el laboratorio no reportó los $\% \mathrm{C}$ y $\% \mathrm{~N}$, mas su proporción $\mathrm{C} / \mathrm{N}$ está dentro del rango de validación y es similar al de las otras muestras.

La calibración de las dataciones arrojó un rango de fechados que van desde los $357 \mathrm{cal}$. AC a 1447 cal. DC, abarcando todos los periodos arqueológicos del área de estudio desde el Arcaico Tardío al PT (Figura 5). En general, la mayoría de estas dataciones concuerdan con las dataciones relativas de acuerdo a los materiales registrados en los contextos mortuorios de los individuos de la muestra; las únicas diferencias se observan en la datación del individuo E15 del sitio CAS 58 y del individuo E20 del sitio CAS 61.

En el primer caso se esperaba que arrojara una fecha en el periodo Arcaico dadas las características de su contexto mortuorio y los materiales registrados en él; en el segundo caso se esperaba un fechado más cercano al rango del PM por tratarse de un contexto vinculado, posiblemente, al Complejo
Las Ánimas. Los alcances de estos resultados se comentarán con más detalle en la discusión de los resultados y a la luz de los resultados obtenidos del análisis de isótopos estables de la dieta.

\section{Isótopos estables de la dieta}

En la Figura 6a se grafican los valores $\delta^{13} \mathrm{Ccol}$ y $\delta^{15} \mathrm{~N}$ obtenidos en las diez muestras provenientes de los siete individuos seleccionados. Los valores $\delta^{13} \mathrm{C}_{\text {col }}$ se encuentran entre los $-18,7$ a $-11 \%$ y sin observarse diferencias significativas al agrupar las muestras de acuerdo a la categoría "edad" ( $\mathrm{p}=0,9)$. Sí se observan diferencias significativas $(\mathrm{p}=0,02)$ al agrupar los valores por cronología absoluta, donde las muestras pre $600 \mathrm{cal}$. DC registran valores $\delta^{13} \mathrm{C}_{\text {col }}$ entre - $18,7 \mathrm{a}-16,6 \%$, y las muestras post $1200 \mathrm{cal}$. DC arrojan valores entre $-15,1$ a $-11 \%$.

Los valores $\delta^{15} \mathrm{~N}$ de las muestras, que van desde los 7,7 a los 12,8\%o, muestran diferencias significativas según las categorías de "edad" $(\mathrm{p}=0,03)$ con valores más elevados en infantes $(\delta=9,7 \%$ o $)$ respecto a niños (i.e. muestras 

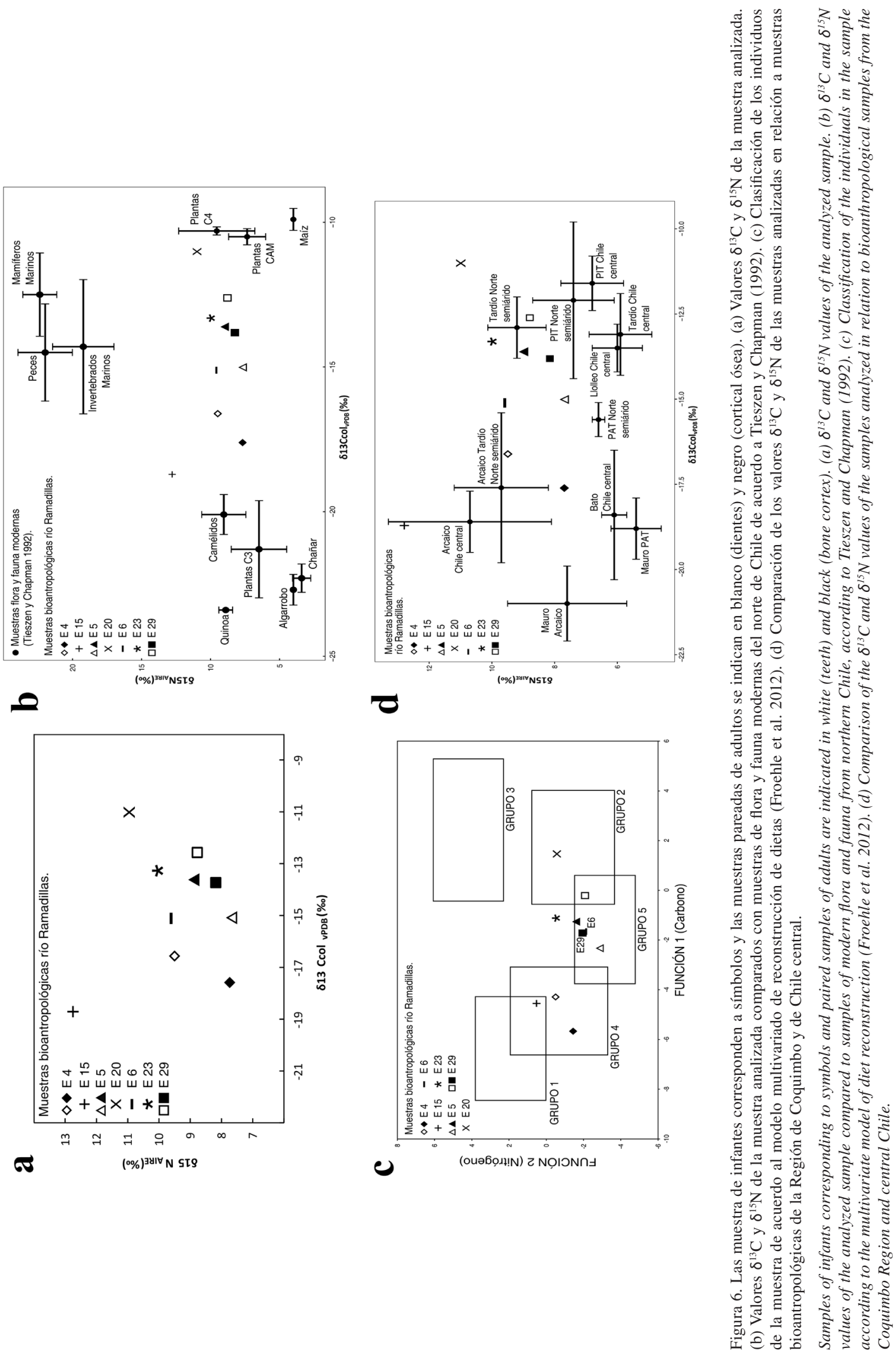
Tabla 3. Valores $\delta^{18} \mathrm{O}_{\text {SMow }}$ de referencia para la Cuenca del Río Copiapó. Los números arábigos corresponden a muestras de aguas superficiales del río Copiapó, mientras que los números romanos indican puntos de muestra de aguas lluvias.

Reference $\delta^{18} O_{S M O W}$ values for the Copiapó River basin. The Arabic numbers list sample points of surface waters from the Copiapó River, while the Roman numbers list rainwater sample points.

\begin{tabular}{|c|c|c|}
\hline Punto muestra* & $\begin{array}{c}\text { Altitud } \\
\text { msm }\end{array}$ & $\begin{array}{l}\delta^{18} \mathrm{O} \% o \\
\text { SMOW }\end{array}$ \\
\hline 1. Desembocadura Río Copiapó & 13 & $-8,6$ \\
\hline 2. Angostura & 64 & $-8,8$ \\
\hline 3. Pabellón & 640 & $-10,1$ \\
\hline 4. La Puerta & 855 & $-10,2$ \\
\hline 5. Embalse Lautaro & 1101 & $-8,5$ \\
\hline 6. Pastillos & 1163 & $-11,9$ \\
\hline 7. Río Manflas & 1519 & $-11,6$ \\
\hline 8. Río Chacay & 1813 & $-13,1$ \\
\hline 9. Río Figueroa & 2339 & $-11,1$ \\
\hline 10. Río Aguas Blancas & 2896 & $-8,8$ \\
\hline 11. Río Turbio & 3110 & $-12,1$ \\
\hline 12. Río Nevado & 3305 & -12 \\
\hline 13. Río Jorquera & 3637 & $-11,2$ \\
\hline 14. Glaciar El Potro & 4970 & $-15,2$ \\
\hline 15. Quebrada Caserones & 4100 & $-13,2$ \\
\hline 16. Quebrada del Medio & 4100 & $-12,7$ \\
\hline I. Hacienda Margarita & 194 & $-4,1$ \\
\hline II. SERNAGEOMIN Copiapó & 375 & $-3,6$ \\
\hline III. Agrícola Tres Soles & 670 & $-4,6$ \\
\hline IV. Fundo El Fuerte & 924 & $-5,4$ \\
\hline V. Copiapó en Pastillo & 1.166 & $-7,4$ \\
\hline VI. Quebrada Seca & 1.516 & $-8,6$ \\
\hline VII. Río Jorquera & 1832 & $-8,5$ \\
\hline VIII. El Potro & 2200 & $-11,2$ \\
\hline
\end{tabular}

dentales de adultos, $\delta=8,7 \%$ ) y adultos (i.e. muestras corticales de adultos, $\delta=8,3 \%$ ). No se observan diferencias significativas según rango cronológico $(\mathrm{p}=0,9)$.

\section{Componentes de las dietas}

Los valores $\delta^{13} \mathrm{C}_{\text {col }}$ y $\delta^{15} \mathrm{~N}$ obtenidos en los individuos de Ramadillas (Tabla 1) descartan el consumo de recursos marinos y señalan que sus dietas descansaban en recursos terrestres, tanto vegetales como animales. La Figura $6 \mathrm{~b}$ muestra los valores $\delta^{13} \mathrm{C}_{\text {col }}$ y $\delta^{15} \mathrm{~N}$ de los individuos de la muestra analizada respecto a los de recursos de flora y fauna modernos del norte de Chile (Tieszen y Chapman 1992) corregidos según discriminación trófica y efecto Suess. Los valores $\delta^{13} \mathrm{C}_{\text {col }}$ de los individuos pre 600 cal. DC, con un rango de $-18,7 \%$ a a $-16,6 \%$, ocuparían una posición más cercana a recursos vegetales $\mathrm{C}_{3}$, mientras que los valores $\delta^{13} \mathrm{C}_{\text {col }}$ de los individuos con fechados posteriores a 1200 cal. DC, con un rango de $-15,1 \%$ a $-11 \%$, tienden a agruparse más cerca de los valores de recursos vegetales CAM y C4. Los valores $\delta^{15} \mathrm{~N}$ se ubican en un rango de entre $7,7 \%$ y $11 \%$ o para el general de la muestra, exceptuando al individuo E15 del sitio CAS $58\left(\delta^{15} \mathrm{~N}=12,8 \%\right.$ ), lo que sugieren el consumo de recursos animales de un nivel trófico similar al de los camélidos ya que se ubican dentro del rango de valores $\delta^{15} \mathrm{~N}$ observados para este recurso.

Al aplicar las funciones discriminantes del modelo predictivo de los recursos de la dieta (Froehle et al. 2012) se observa que los individuos de la muestra incorporan recursos $\mathrm{C}_{4}$ a su dieta con distintas proporciones al distribuirse estos entre los grupos 2 , 4 y 5 (Figura 6c); se descarta el consumo de recursos marinos dado que no se observaron casos dentro de la dispersión del grupo 3 (dieta general 50:50\% de recursos $\mathrm{C} 3$ y $\mathrm{C} 4$, con proteínas de origen marino). Los individuos E4 y E15, con dataciones pre $600 \mathrm{cal}$. DC, se ubican cerca del centro de la distribución del grupo 4, que correspondería a una dieta general con una razón de 70:30\% de recursos C3:C4 y con un $65 \%$ o más de consumo de proteínas $\mathrm{C}_{3}$. El resto de los individuos, con dataciones posteriores a $1200 \mathrm{cal}$ DC, se distribuyen en las áreas que corresponden a los grupos 2 y 5 , los cuales corresponden a dietas con introducción de recursos $\mathrm{C}_{4}$ ya sea a través de la dieta general como el grupo 5 (70\% dieta general con recursos $\mathrm{C}_{4}$ y $65 \%$ o más de proteínas $\mathrm{C}_{3}$ ), o por el consumo de proteínas $\mathrm{C}_{4}$ según el caso del grupo 2 (70\% dieta general con recursos $\mathrm{C}_{4}$ y más del $50 \%$ de proteínas $\mathrm{C}_{4}$ ). La distribución de los individuos de la muestra en relación a los valores isotópicos de los recursos flora y fauna (Figura 6b) es verosímil con la distribución observada en el modelo predictivo de los recursos de la dieta (Figura 6c).

\section{Comparación con áreas vecinas}

Los valores $\delta^{13} \mathrm{C}_{\text {col }}$ y $\delta^{15} \mathrm{~N}$ de los individuos muestreados presentan una variabilidad similar a la de otras muestras bioantropológicas de similar 
cronología y periodo cultural registradas en la Región de Coquimbo y en Chile central (Figura 6c). Los individuos de Ramadillas con fechados previos al 600 cal. DC, individuos E4 y E15, se agrupan junto al rango de valores de los individuos del periodo Arcaico Tardío de la Región de Coquimbo y Arcaico de Chile central, para los cuales se ha sugerido una dieta con mayor énfasis en recursos vegetales $\mathrm{C} 3$ y proteínas de origen animal. Los valores $\delta^{13} \mathrm{C}_{\text {col }}$ y $\delta^{15} \mathrm{~N}$ de los individuos de Ramadillas con fechados posteriores al 1200 cal. DC se agrupan con los valores de bioantropológicas del PIT y PT de la Región de Coquimbo, los que darían cuenta de dietas con un consumo de proteínas de origen animal de un nivel trófico similar, junto con un mayor consumo de recursos vegetales $\mathrm{C}_{4}$.

\section{Análisis de movilidad humana}

Los valores $\delta^{18} \mathrm{O}_{\text {SMow }}$ disponibles de las aguas superficiales y aguas lluvias de la Cuenca del Río Copiapó se muestran en la Tabla 3 junto con la cota de altitud (msm) de los puntos de muestreo. Mientras los valores de las aguas lluvias señalan el empobrecimiento de estas en ${ }^{18} \mathrm{O}$ desde la costa hacia al interior y en función al aumento de altitud, con un rango de valores entre los $-3,6 \%$ a los $-11,2 \%$ o (Tabla 3, números romanos), los valores observados en las aguas superficiales del Río Copiapó en curso bajo y medio se muestran más negativos en relación a los de las aguas lluvias, con un rango costacordillera entre los $-8,6 \%$ o a $-15,2 \%$ o (Tabla 3, números arábigos). Esta diferencia se explicaría porque en el curso medio y bajo del Río Copiapó existen afloramientos de aguas subterráneas provenientes de la cordillera que contribuyen con flujos de aguas más empobrecidos procedentes desde el curso alto del río, sobre $3.000 \mathrm{msm}$ (Troncoso et al. 2012).

Los valores $\delta^{18} \mathrm{O}_{\mathrm{DW}}$ de los individuos analizados varían entre $-8,4 \%$ a $-11,5 \%$ o. Este rango se encuentra dentro de los valores $\delta^{18} \mathrm{O}_{\text {SMow }}$ registrados en las aguas superficiales del curso medio del Río Copiapó entre los 0 a $4.000 \mathrm{msm}$ (Tabla 3). Los valores $\delta^{18} \mathrm{O}_{\mathrm{DW}}$ de las muestras de individuos infantes y adultos, tanto dentales como de cortical ósea, no muestran diferencias estadísticamente significativas entre sí $(\mathrm{p}=0,64)$. Sí se observan diferencias significativas entre los valores $\delta^{18} \mathrm{O}_{\mathrm{DW}}$ según rango cronológico $(\mathrm{p}=0,016)$. Los $\delta^{18} \mathrm{O}_{\mathrm{DW}}$ de las muestras con fechados anteriores al 600 cal. DC varían en un rango de valores entre -8,4 a 9,3\%o, mientras que el rango de los valores de las muestras con fechados posteriores al 1200 cal. DC varía de $-9,7$ a $-11,5 \%$ o. La Figura 7 compara la distribución de los valores $\delta^{18} \mathrm{O}_{\mathrm{DW}}$ de las muestras con fechados anteriores al $600 \mathrm{cal}$. DC y posteriores al $1200 \mathrm{cal}$. DC con $\operatorname{los} \delta^{18} \mathrm{O}_{\text {SMow }}$ de las aguas superficiales y aguas lluvias de la Cuenca del Río Copiapó. De acuerdo a este gráfico, los valores $\delta^{18} \mathrm{O}_{\mathrm{DW}}$ de las muestras bioantropológicas con dataciones pre $600 \mathrm{cal}$. DC se ubican dentro del rango de valores obtenidos en aguas del curso bajo y medio de la Cuenca del Río Copiapó, entre los 0 a $1.000 \mathrm{msm}$; mientras que los valores $\delta^{18} \mathrm{O}_{\mathrm{DW}}$ de las muestras bioantropológicas con dataciones post 1200 cal. DC se agrupan más bien dentro del rango valores de recursos hídricos obtenidos entre los 1.000 a $4.000 \mathrm{msm}$.

\section{Discusión}

Las dataciones permitieron ubicar cronológicamente a los siete individuos analizados, junto con sus contextos mortuorios, dentro del rango temporal de los cinco periodos de la secuencia cultural de la prehistoria de la Región de Atacama: Arcaico, PAT, PM, PIT y PT. Sin embargo, ciertas características de los contextos mortuorios introducen aspectos a considerar en sus adscripciones cronoculturales, las cuales se discuten a tomando en cuenta los datos isotópicos derivados de la dieta y la información relevada de los contextos mortuorios en que fueron hallados, así como antecedentes de contextos arqueológicos de la Región de Coquimbo y de Chile Central.

La fecha del individuo E4 del sitio CAS 61 (357$146 \mathrm{cal}$. AC) lo adscribe al Arcaico Tardío según la cronología propuesta en la literatura (Cervellino 1998), lo cual es corroborado por su contexto mortuorio convirtiéndolo en el único reportado para tal periodo en la Precordillera de Copiapó. La fecha del individuo E15 del sitio CAS 58, 421-566 cal. DC, lo adscribe al periodo Alfarero Temprano. Sin embargo, la ausencia de material cerámico asociado al entierro y la presencia de tres puntas de proyectil de factura arcaica (Figura 2) junto a desechos de talla lítica, fragmentos óseos de fauna y eventos de quema directamente asociados al esqueleto asemejan su contexto mortuorio al del individuo E4 adscrito a fines del Arcaico Tardío. El análisis de dieta 


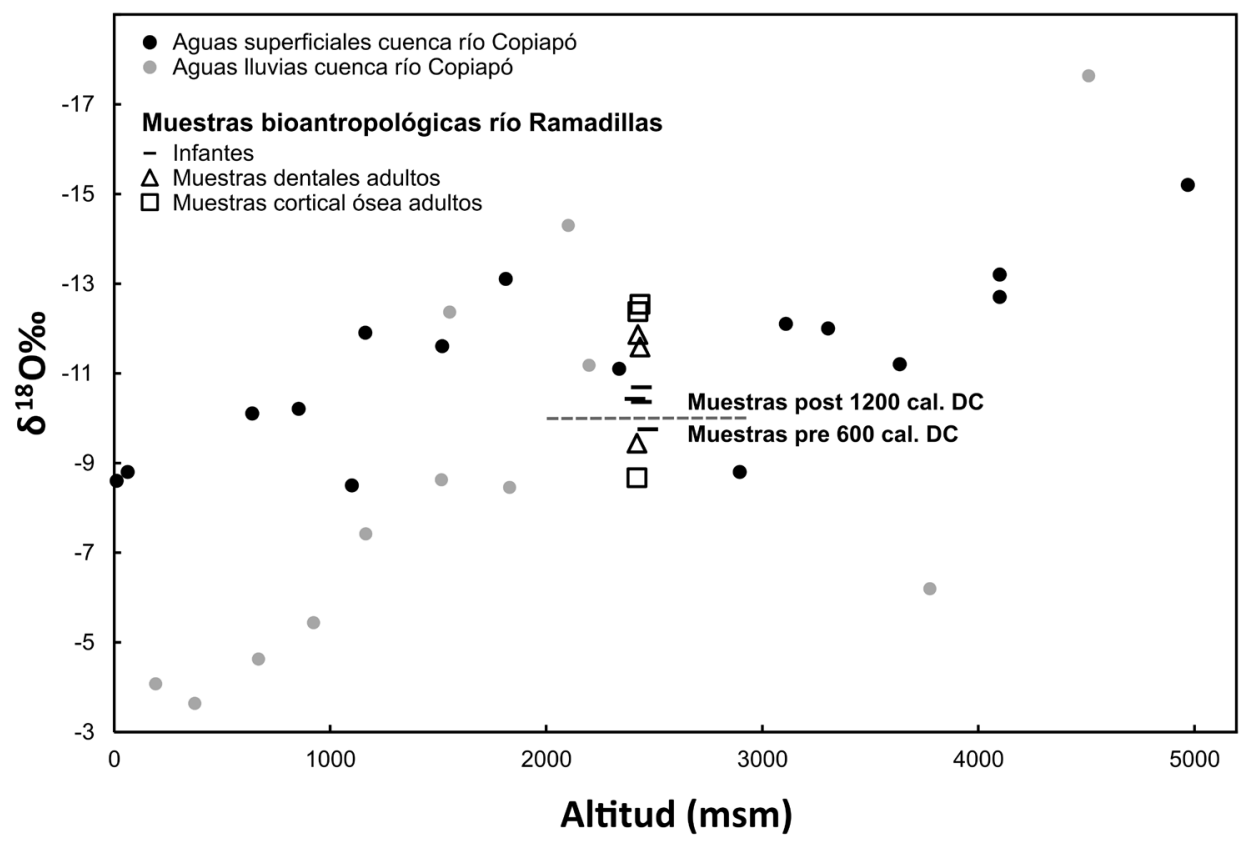

Figura 7. Valores $\delta^{18} \mathrm{O}_{\mathrm{DW}}$ de la muestra analizada respecto a la variación del $\delta_{18} \mathrm{O}_{\text {SMOW }}$ en las aguas superficiales de laCuenca del Río Copiapó de acuerdo a la altitud; la línea punteada indica la separación entre las muestras con rango temporal pre 600 cal. DC y post $1200 \mathrm{cal}$. DC.

$\delta^{18} O_{D W}$ values of the sample analyzed with respect to the variation of $\delta^{18} O_{S M O W}$ in the surface waters of the Copiapó River basin according to altitude; the dotted line indicates the separation between samples with pre $600 \mathrm{cal}$. DC and post $1200 \mathrm{cal}$. DC time range.

de estos dos individuos, por su parte, señala un consumo predominante de recursos vegetales $\mathrm{C}_{3}$ (Figuras 6b y 6c), junto con el consumo de recursos de nivel trófico similar al de camélidos, especie que podría estar siendo incorporada a la dieta de acuerdo al análisis de los fragmentos óseos de fauna asociada a los sitios presentados. Además, los isótopos de la dieta de estos dos individuos tienden a agruparse con los de otras muestras bioantropológicas adscritas al periodo Arcaico del Norte Semiárido y de Chile Central (Figura 6d). Para evaluar estas posibilidades consideramos necesario levantar datos isotópicos de los recursos de flora y fauna locales de la región.

De todos modos, considerando tanto los datos del contexto mortuorio como los de isótopos estables de la dieta, es posible sugerir que el individuo E15 del sitio CAS 58 podría estar vinculado a grupos que mantuvieron un modo de vida cazador recolector que alcanzó una continuidad temporal en el sector de la Cuenca del Río Ramadillas hasta por lo menos el 421-566 cal. DC. Antecedentes de la continuidad de este modo de vida han sido reportados en la Región de Coquimbo y en Chile Central. En el Valle Pama (Provincia del Limarí, Región de Coquimbo) se han registrado contextos arqueológicos que estarían indicando la coexistencia entre grupos cazadores recolectores con comunidades alfareras tempranas entre el 250 y el 1000 DC (Méndez et al. 2009), en donde los sitios se caracterizan por su tamaño pequeño, diversa funcionalidad, manufacturación y descarte de instrumentos líticos tallados o de molienda y bajo descarte de recipientes cerámicos pequeños. Más al sur en Chile Central, en el curso alto de la Cuenca del Río Maipo, se han registrado sitios adscritos a cazadores-recolectores con evidencias de actividades humanas muy específicas y de carácter logístico, ubicados preferentemente en quebradas secundarias y laderas de cerros, cuyas dataciones de entre el $350 \mathrm{AC}$ al $950 \mathrm{DC}$ comprenden todo el PAT de la región (Cornejo y Sanhueza 2003). En vista de estos antecedentes, del conjunto de aspectos registrados para el individuo E15 
en su contexto mortuorio (presencia de puntas de proyectil de factura arcaica y de desechos líticos, restos óseos de fauna, fogones y bolones de piedras asociados a los cuerpos, y ausencia de material cerámico), de asentamiento (ocupación de espacios ubicados en una quebrada secundaria precordillerana) y de dieta, es posible sugerir una continuidad del modo de vida cazador recolector en la Cuenca del Río Ramadillas hasta por lo menos el 500 DC. Considerando el carácter exploratorio del trabajo presentado, es necesario poner el énfasis de que son necesarios nuevos estudios sistemáticos en el área analizada para explorar esta propuesta.

Según la cronología vigente, los fechados del individuo E5 (1279-1382 cal. DC) y del individuo E20 (1287-1388 cal. DC) del sitio CAS 61 se adscriben al PIT. No obstante, en el contexto mortuorio del individuo E5 se registró parte de una vasija Ánimas y una espátula de hueso (Figura 3a y $3 b$ ), y en el contexto mortuorio del infante E20 se registró una vasija con mamelones aparentemente Ánimas (Figura 3c), lo que por datación relativa los adscribe al periodo Medio. De acuerdo al rango temporal propuesto para la expresión del complejo cultural Las Ánimas tanto en los valles de Copiapó y Huasco, entre los 640 a 1100 años DC, como en el Valle del Elqui, 740 a 1045 años DC (Troncoso y Pavlovic 2013), los fechados de los individuos E5 y E20 del sitio CAS 61 resultan más tardíos, sugiriendo la persistencia temporal del complejo Las Ánimas en la Cuenca del Río Ramadillas. Cabe mencionar, finalmente, que los fechados de los individuos E5 y E20 de Ramadillas son similares al obtenido en el sitio Plaza de Coquimbo (11211394 cal. DC), el cual se ha considerado demasiado tardío (Troncoso et al. 2016).

La fecha del infante E6 del sitio CAS 61 (13171407 cal. DC) lo adscribe al periodo Intermedio Tardío, lo cual es coherente con su contexto mortuorio en el que fue hallado un puco diagnóstico de la Cultura Copiapó. En el contexto mortuorio de los infantes E23 y E24 del sitio CAS 61, fechado en 1323-1423 cal. DC, se hallaron asociados a dos pucos de cerámica: uno diagnóstico de la Cultura Copiapó y el otro posiblemente Diaguita-Inca lo cual permite señalar la presencia de elementos culturales Diaguita-Inca en la cuenca hidrográfica del Río Copiapó un poco antes a la fecha de 1450 DC en que se ha establecido su ingreso (Castillo 1998), y sugerir una eventual transición entre el periodo Intermedio Tardío y el Tardío en el área de estudio. Finalmente, el fechado del individuo E29 del sitio CAS 61, 1410-1447 cal. DC, lo ubica en el periodo Tardío. Asociado a este individuo se halló una vasija diagnóstica Diaguita-Inca.

Los análisis de isótopos estables de dieta de los individuos de la Cuenca del Río Ramadillas fechados entre 1279 a 1447 cal. DC sugieren un mayor consumo de recursos vegetales $\mathrm{C}_{4}$, junto con el consumo de recursos terrestres de nivel trófico similar al de camélidos del norte grande (Tieszen y Chapman 1992). La similitud de los valores $\delta^{13} \mathrm{C}$ de estos individuos con los de las muestras bioantropológicas del PIT y PT de la Región de Coquimbo y Chile central, en los que se ha documentado el consumo y cultivo del maíz (Alfonso-Durruty et al. 2017; Falabella et al. 2008; Planella et al. 2014), permiten plantear esta tendencia hacia un mayor consumo de recursos vegetales $\mathrm{C}_{4}$. En función de lo anterior, es posible sugerir que en el área del Río Ramadillas se estaría dando, al menos, el procesamiento de recursos vegetales $\mathrm{C}_{4}$ como el maíz o el amaranto, tal como se ha indicado para los sitios de la Región de Coquimbo (Becker et al. 2015, Alfonso-Durruty et al. 2017). La presencia de marlos de maíz en algunos de los contextos mortuorios post $1200 \mathrm{cal}$. DC del sitio CAS 61, así como el registro en superficie de instrumentos de molienda y palas líticas en el sitio CAS 58 permitirían dar sustento a esta propuesta.

No hay diferencias temporales en las proporciones de los isótopos de nitrógeno de las muestras analizadas de los individuos de Ramadillas, lo cual sugiere el consumo constante de recursos terrestres de nivel trófico similar al de camélidos. La presencia de restos de estos animales identificados en los análisis zooarqueológicos del sitio CAS 58 y CAS 61 sugiere su consumo. Al comparar los individuos de la Cuenca del Río Ramadillas con los de la Región de Coquimbo, en los que se ha sugerido el consumo de camélidos a partir de líneas de base isotópicas de los recursos locales de esa región (Alfonso-Durruty et al. 2017; Becker et al. 2015), se observan que están dentro del mismo rango de valores $\delta^{15} \mathrm{~N}$. Sin embargo, se debe ponderar que, de la muestra analizada, cuatro individuos corresponden lactantes cuyos valores $\delta^{15} \mathrm{~N}$ más elevados se explicarían en parte por el factor de enriquecimiento trófico del amamantamiento (Fogel et al. 1989; Fuller et al. 2006). Considerando un factor conservador de 
enriquecimiento de $3 \%$ en el $15 \mathrm{~N}$ de las muestras de infantes producto de la lactancia, la sustracción de este factor a los valores $\delta^{15} \mathrm{~N}$ de estos individuos arroja un rango entre 6,6 a 9,8\%o, el cual aún se ubica dentro de la variación de valores $\delta^{15} \mathrm{~N}$ de los camélidos utilizados como referencia y graficados en la Figura 6b. Considerando que los valores isotópicos registrados en individuos lactantes reflejan, en parte, la dieta de las mujeres que los amamantan, es posible sugerir que mediante la lactancia se estarían introduciendo indirectamente en la dieta de los infantes recursos terrestres de un nivel trófico similar al de los camélidos.

El rango de valores $\delta^{18} \mathrm{O}$ observados en los individuos de los sitios CAS 58 y CAS 61 del Río Ramadillas sugiere circuitos de movilidad restringidos a cotas de altura similares a las del área de estudio, por sobre los $1.500 \mathrm{msm}$. Los valores $\delta^{18} \mathrm{O}$ de los individuos E4 y E15, que corresponderían a los que cuentan con las dataciones más tempranas, son ligeramente mayores respecto a los registrados en las muestras de los tres infantes (individuos E6, E20 y E23) y dos adultos más tardíos (E5, y E29). Esta escasa diferencia, de aproximadamente $1,7 \%$, entre los individuos tempranos y tardíos se podría explicar considerando que la muestra de individuos más tardíos está compuesta por tres lactantes cuyos valores $\delta^{18} \mathrm{O}$ más altos, en relación a los otros dos adultos de data tardía, se explicarían por el mayor enriquecimiento de ${ }^{18} \mathrm{O}$ de la leche humana respecto a las aguas locales, lo que implicaría un aumento de aproximadamente $1 \%$ en el valor $\delta^{18} \mathrm{O}$ de esos casos (Britton et al. 2015), y que en consecuencia los acercaría más a los valores de los individuos con fechados más tempranos según se puede apreciar en la Figura 7. Otro factor a tener en consideración es que, tratándose de poblaciones alfareras, los valores $\delta^{18} \mathrm{O}$ de las aguas consumidas podrían sufrir modificaciones producto de las técnicas de preparación de alimentos mediante cocciones y/o la producción de bebidas alcohólicas y no alcohólicas. Según estudios experimentales recientes, se ha observado un enriquecimiento de entre 2,3 a $5 \%$ en los valores $\delta^{18} \mathrm{O}$ de los líquidos después de realizadas las preparaciones culinarias (Brettell et al. 2012; Royer et al. 2017). Para comprobar las movilidades en los valles interiores y cordilleranos se sugiere tomar muestras del agua de los ríos del área de estudio y analizar sus valores $\delta^{18} \mathrm{O}$, así como analizar un mayor número de individuos, especialmente de aquellos que puedan ser registrados en contextos mortuorios del periodo Arcaico.

\section{Conclusiones}

Los datos presentados constituyen los primeros de este tipo para la Cuenca del Río Ramadillas y se suman a los pocos que existen para la Región de Atacama. Los fechados de los cuatro lactantes y de los tres adultos analizados cubren un lapso de casi 2000 años $(357 \mathrm{cal}$. AC a 1447 cal. DC). En base a fechados absolutos de muestras bioantropológicas, a la ponderación de las características de los contextos mortuorios donde se recuperaron los individuos, y de acuerdo al análisis de dieta mediante isótopos estables, la muestra analizada pudo ser caracterizada arqueológicamente en un área que a la fecha carece de estudios sistemáticos y actualizados durante los últimos 20 años; lo que nos ha permitido una aproximación preliminar al comportamiento de los contextos mortuorios del área en cuestión respecto a los periodos propuestos para la arqueología de la región (Niemeyer et al. 1998; Troncoso et al. 2016). En función de lo anterior, se ha sugerido la pervivencia del modo de vida cazadoresrecolector del Arcaico Tardío durante el PAT de acuerdo a las características del contexto mortuorio y el análisis de los isótopos de la dieta del individuo E15. Para el Complejo Las Ánimas se plantea una posible coexistencia con la cultura Copiapó de acuerdo a los resultados obtenidos para el contexto mortuorio de los individuos E5 y E20, así como la posible coexistencia de grupos de la Cultura Copiapó con grupos Diaguita-Inca en el área de estudio en función de la información aportada por el análisis del contexto mortuorio de los individuos E23 y E24.

Los análisis de dieta sugieren el consumo de recursos terrestres de nivel trófico similar al de camélidos. La diferencia más importante se observó en el consumo de recursos vegetales entre los individuos con fechados previos al $600 \mathrm{cal}$. DC respecto a los individuos con fechas posteriores al $1200 \mathrm{cal}$. DC. En estos últimos se observó un mayor consumo de recursos vegetales $\mathrm{C}_{4}$, posiblemente asociado a prácticas de 
procesamiento de cultivos $\mathrm{C}_{4}$ como el amaranto y/o el maíz.

Los análisis de movilidad sugirieron la ocupación de espacios cercanos al área donde fueron enterrados, posiblemente entre el curso medio del Río Copiapó y la Precordillera de los Andes. En el caso de los individuos más tempranos, para los que se plantea un modo de vida cazador-recolector, el rango de movilidad abarcaría ambientes del curso medio del Río Copiapó, en torno a los $1.000 \mathrm{msm}$, mientras que los individuos con fechados posteriores al 1200 cal. DC, y posiblemente con un modo de vida más sedentario, habrían ocupado ambientes entre el curso medio y precordillerano de la cuenca hidrográfica del Río Copiapó.

Se debe insistir en la naturaleza exploratoria de este trabajo dada su muestra acotada; por esta razón los resultados presentados, junto con los alcances de las propuestas que surgen a partir de ellos, se plantean con la intención de alimentar futuras hipótesis de investigación que contribuyan al estímulo de nuevas investigaciones sistemáticas en la Región de Atacama. Consideramos necesario poner el énfasis en la importancia de integrar el registro detallado de los contextos mortuorios para establecer los criterios de muestreo para generar y analizar datos de naturaleza más arqueométrica como los isótopos estables de la dieta. La información del contexto mortuorio, de acuerdo a la densidad del registro de este, constituye un aporte sustancial a los resultados que se pueden obtener los análisis de isótopos estables; especialmente cuando estos análisis deben abordar una cantidad limitada de individuos disponibles con tal de permitir que, a futuro, sea posible integrar más individuos o contextos de esta colección dentro de investigaciones sistemáticas que se desarrollen al margen de los apremios administrativos vinculados a la arqueología de contrato.

Agradecimientos: A las y los profesionales de Antropología Física y Arqueología que formaron parte de las labores de recuperación y análisis bioantropológicos del Proyecto Caserones. Especial mención a Mónica Rodríguez, Marucela Pizarro, Rodrigo Retamal, Margarita Rebolledo, Patricia Thielemann, Francisco Castex y Álvaro Olguín. Nuestros agradecimientos también a Sergio Morales, quien facilitó la base de datos con la georeferenciación de los sitios arqueológicos de la Región de Atacama. Agradecemos también a Pablo Gómez de OSTeam Ltda. por su ayuda en la elaboración de las estrategias de muestreo para los análisis bioarqueológicos aquí presentados. Finalmente, al Consejo de Monumentos Nacionales (CMN) de Chile por permitirnos el envío de las muestras que fueron analizadas en Estados Unidos (Ordenanza $\mathrm{N}^{\circ}$ 2049/04 Mayo de 2017). Agradecemos a los revisores anónimos del manuscrito original cuyas observaciones contribuyeron a mejorar la presentación de este trabajo.

\section{Referencias Citadas}

Alfonso-Durruty, M., A. Troncoso, P. Larach, C. Becker y N.Misarti 2017. Maize (Zea mays) consumption in the southern andes $\left(30^{\circ}-31^{\circ} \mathrm{S}\right.$. Lat): Stable isotope evidence (2000 BCE-1540 CE). American Journal of Physical Anthropology 164:148-162.

Ambrose, S. 1986. Stable carbon and nitrogen isotope analysis of human and animal diet in Africa. Journal of Human Evolution 15:707-731.

Ambrose, S.H. 1990. Preparation and characterization of bone and tooth collagen for isotopic analysis. Journal of Archaeological Science 17:431-451.

Ambrose, S.H., B.M. Butler, D.B. Hanson, R.L. HunterAnderson y H.W. Krueger 1997. Stable isotopic analysis of human diet in the Marianas Archipelago, Western Pacific. American Journal of Physical Anthropology 104:343-361.

Becker, C., M. Alfonso, N. Misarti, A. Troncoso y P. Larach 2015. Isótopos estables y dieta en poblaciones prehispánicas del norte semiárido $\left(30^{\circ}-32^{\circ}\right.$ lat. S.): una primera aproximación desde el arcaico tardío hasta el período Incaico. Boletín del Museo Nacional de Historia Natural 64:107-119.
Bocherens, H. y D. Drucker 2003. Trophic level isotopic enrichment of carbon and nitrogen in bone collagen: case studies from recent and ancient terrestrial ecosystems. International Journal of Osteoarchaeology 13:46-53.

Brettell, R., J. Montgomery y J. Evans 2012. Brewing and stewing: the effect of culturally mediated behaviour on the oxygen isotope composition of ingested fluids and the implications for human provenance studies. Journal of Analytical Atomic Spectrometry 27:778-785.

Britton, K., B.T. Fuller, T. Tütken, S. Mays y M.P. Richards 2015. Oxygen isotope analysis of human bone phosphate evidences weaning age in archaeological populations. American Journal of Physical Anthropology 157:226-241.

Bronk Ramsey, C. 2009. Bayesian Analysis of Radiocarbon Dates. Radiocarbon 51:337-360.

Brown, T.A. y K. Brown 2011. Biomolecular Archaeology: An Introduction. John Wiley \& Sons, Chichester, West Sussex.

Bryant, D.J. y P.N. Froelich 1995. A model of oxygen isotope fractionation in body water of large mammals. Geochimica et Cosmochimica Acta 59:4523-4537. 
Budd, P., A. Millard, C. Chenery, S. Lucy y C. Roberts 2004. Investigating population movement by stable isotope analysis: a report from Britain. Antiquity 78:127-141.

Budd, P., J. Montgomery, J. Evans y C. Chenery 2001. Combined $\mathrm{Pb}$-, Sr-and $\mathrm{O}$-isotope analysis of human dental tissue for the reconstruction of archaeological residential mobility. En Plasma Source Mass Spectrometry The New Millennium, editado por G Holland y S. Tanner, pp. 311-326. The Royal Society of Chemistry, Cambridge.

Buikstra, J.E. y D.H. Ubelaker 1994. Standards for Data Collection from Human Skeletal Remains: Proceedings of a Seminar at the Field Museum of Natural History. Arkansas Archaeological Survey, Fayetteville.

Castillo G. 1989. Agricultores y pescadores del Norte Chico: el complejo Las Ánimas (800 a 1.200 d.C.). En Culturas de Chile: Prehistoria, desde sus Orígenes hasta los Albores de la Conquista, editado por J. Hidalgo, V. Schiappacasse, H. Niemeyer, C. Aldunate e I. Solimano, pp. 265-276. Andrés Bello, Santiago

Castillo G. 1998. Los períodos Intermedio Tardío y Tardío: desde la cultura Copiapó al dominio Inca. En Culturas Prehistóricas de Copiapó, editado por H. Niemeyer, M. Cervellino y G. Castillo, pp. 163-282. Museo Regional de Atacama, Santiago.

Cervellino M. 1998. El periódo arcaico en la Región de Atacama. Caza-recolección y pesca marítica (9000 años a 100 años antes de cristo). En Culturas Prehistóricas de Copiapó, editado por H. Niemeyer, M. Cervellino y G. Castillo, pp. 3960. Museo Regional de Atacama, Santiago.

Coplen T. 1988. Normalization of oxygen and hydrogen isotope data. Chemical Geology: Isotope Geoscience section 72:293-297.

Cornejo, L., D. Jackson y M. Saavedra 2016. Cazadoresrecolectores arcaicos al sur del desierto (ca. 11.000 a 300 años a.C). En Prehistoria en Chile. Desde sus Primeros Habitantes hasta los Incas, editado por F. Falabella, M. Uribe, L. Sanhueza, C. Aldunate y J. Hidalgo, pp. 285-318. Editorial Universitaria, Santiago.

Cornejo, L. y L. Sanhueza 2003. Coexistencia de Cazadores Recolectores y Horticultores Tempranos en la Cordillera Andina de Chile Central. Latin American Antiquity 14:389407.

Chenery, C.A., V. Pashley, A.L. Lamb, H.J. Sloane y J.A. Evans 2012. The oxygen isotope relationship between the phosphate and structural carbonate fractions of human bioapatite. Rapid Communications in Mass Spectrometry 26:309-319.

Cherkinsky. A., R.A. Culp, D.K. Dvoracek y J.E. Noakes 2010. Status of the AMS facility at the University of Georgia Nuclear Instruments and Methods in Physics Research Section B: Beam Interactions with Materials and Atoms 268:867-870

Daux, V., C. Lécuyer, M.A. Héran, R. Amiot, L. Simon, F. Fourel, F. Martineau, N. Lynnerup, H. Reychler y G. Escarguel 2008. Oxygen isotope fractionation between human phosphate and water revisited. Journal of Human Evolution 55:1138-1147.

DeNiro, M. y S. Epstein 1978. Influence of diet on the distribution of carbon isotopes in animals. Geochimica et Cosmochimica Acta 42:495-506.
DeNiro, M. y S.Epstein 1981. Influence of diet on the distribution of nitrogen isotopes in animals. Geochimica et Cosmochimica Acta 45:341-351.

DeNiro, M.J. 1985. Postmortem preservation and alteration of in vivo bone collagen isotope ratios in relation to palaeodietary reconstruction. Nature 317:806-809.

Falabella, F., D. Pavlovic, M.T. Planella y L. Sanhueza 2016. Diversidad y heterogeneidad cultural y social en Chile Central durante los periodos Alfarero Temprano e Intermedio Tardío (300 años a.C. a 1.450 años d.C.). En Prehistoria en Chile. Desde sus Primeros Habitantes hasta los Incas, editado por F. Falabella, M. Uribe, L. Sanhueza, C. Aldunate y J. Hidalgo, pp. 365-399. Editorial Universitaria, Santiago.

Falabella, F., M.T. Planella, E. Aspillaga, L. Sanhueza y R.H. Tykot 2007. Dieta en sociedades alfareras de Chile Central: Aporte de análisis de isótopos estables. Chungara Revista de Antropología Chilena 39 (1):5-27.

Falabella, F., M.T. Planella y R.H. Tykot 2008. El maíz (Zea mays) en el mundo prehispánico de Chile central. Latin American Antiquity 19:25-46.

Fogel, M.L., N. Tuross y D.W. Owsley 1989. Nitrogen isotope tracers of human lactation in modern and archaeological populations. Carnegie Institution of Washington Yearbook 88:111-117.

Froehle, A.W., C.M. Kellner y M.J. Schoeninger 2010. FOCUS: effect of diet and protein source on carbon stable isotope ratios in collagen: follow up to Warinner and Tuross (2009). Journal of Archaeological Science 37:2662-2670.

Froehle, A.W., C.M. Kellner y M.J. Schoeninger 2012. Multivariate carbon and nitrogen stable isotope model for the reconstruction of prehistoric human diet. American Journal of Physical Anthropology 147:352-369.

Fuller, B.T., J.L. Fuller, D.A. Harris y R.E.M. Hedges 2006. Detection of breastfeeding and weaning in modern human infants with carbon and nitrogen stable isotope ratios. American Journal of Physical Anthropology 129:279-293.

Gaete, N. 1999. Evidencias de dominio incaico en la región de Atacama: Hacia una sistematización de la ocupación de la cuenca del río Jorquera. Estudios Atacameños 223-236.

Garrido, F. 2006. ¿Qué sucedió en Copiapó? Una aproximación a la Cultura Copiapó desde la Alfarería. Actas $5^{\circ}$ Congreso Chileno de Antropología: Antropología en Chile: balances y perspectivas, pp. 539-551. LOM, Santiago.

Garrido, F. 2007. El Camélido Sagrado y el Hombre de los Valles: Una Aproximación a la Cultura Copiapó y sus Relaciones a Partir de la Alfarería. Memoria para optar al título de Arqueólogo, Departamento de Antropología, Universidad de Chile, Santiago.

Garrido, F. 2010. El camélido sagrado y el hombre de los valles: la alfarería de la cultura Copiapó. Actas del XVII Congreso Nacional de Arqueológía Chilena, pp. 217-228. Sociedad Chilena de Arqueología, Valdivia.

Garrido, F. y C. Morales 2019. Displays of violence and power at the Edge of the Empire: Provincial trophy heads during Inca times. Latin American Antiquity 30:606-623.

Gómez, P. y A. Pacheco 2016. Movilidad y dieta en el valle de El Mauro ( $\left.31^{\circ} 57^{`} \mathrm{~S}-71^{\circ} 01^{`} \mathrm{~W}\right)$, norte semiárido de Chile, entre el 8350-929 cal. AP. Comechingonia, Revista de Arqueología 20:51-79. 
Gustafson, G. y G. Koch 1974. Age estimation up to 16 years of age based on dental development. Odontol Revy 25:297-306.

Harrison, R.G. y M.A. Katzenberg 2003. Paleodiet studies using stable carbon isotopes from bone apatite and collagen: examples from Southern Ontario and San Nicolas Island, California. Journal of Anthropological Archaeology 22:227-244.

Hogg, A.G., Q. Hua, P.G. Blackwell, M. Niu, C.E. Buck, T.P. Guilderson, T.J. Heaton, J.G. Palmer, P.J. Reimer y R.W. Reimer 2013. SHCal13 Southern Hemisphere calibration, 0-50,000 years cal BP. Radiocarbon 55:1889-1903.

Kellner, C. y M. Schoeninger 2007. A simple carbon isotope model for reconstructing prehistoric human diet. American Journal of Physical Anthropology 133:1112-1127.

Knudson, K.J. 2009. Oxygen isotope analysis in a land of environmental extremes: the complexities of isotopic work in the Andes. International Journal of Osteoarchaeology 19:171191.

Kohn, M., M, Schoeninger y J. Valley 1996. Herbivore tooth oxygen isotope compositions: Effects of diet and physiology. Geochimica et Cosmochimica Acta 60:3889-3896.

Lee-Thorp, J.A., J.C. Sealy y N.J. van der Merwe 1989. Stable carbon isotope ratio differences between bone collagen and bone apatite, and their relationship to diet. Journal of Archaeological Science 16:585-599.

Lorca, M. 2011. Hidrogeología e Hidrogeoquímica de la Cuenca de la Quebrada Paipote, Región de Atacama. Tesis para optar al grado de Magíster en Ciencias, Departamento de Geología, Universidad de Chile, Santiago.

Maldonado, A., M.E. De Porras, A. Zamora, M. Rivadeneira y A.M. Abarzúa 2016. El escenario geográfico y paleoambiental de Chile. En Prehistoria en Chile. Desde sus Primeros Habitantes hasta los Incas, editado por F. Falabella, M. Uribe, L. Sanhueza, C. Aldunate y J. Hidalgo, pp. 23-70. Editorial Universitaria, Santiago.

Méndez, C.A., M. Troncoso, D. Jackson y D. Pavlovic 2009. Movilidad y uso del espacio entre cazadoresrecolectores tardíos en espacios cordilleranos del Norte Semiárido de Chile. Intersecciones en Antropología 10:311-326.

Niemeyer, H. 1998a. El Periodo Medio, Complejo Las Ánimas. En Culturas Prehistóricas de Copiapó, editado por H. Niemeyer, M. Cervellino y G. Castillo, pp. 115-162. Museo Regional de Atacama, Santiago.

Niemeyer, H. 1998b. El período temprano en del horizonte agroalfarero en Copiapó. En Culturas Prehistóricas de Copiapó, editado por H. Niemeyer, M. Cervellino y G. Castillo, pp. 61-114. Museo Regional de Atacama, Santiago.

Niemeyer, H., G. Castillo y M. Cervellino 1989. Los Primeros ceramistas del Norte Chico: complejo el Molle. En Culturas de Chile: Prehistoria, desde sus Origenes hasta los Albores de la Conquista, editado por J. Hidalgo, V. Schiappacasse, H. Niemeyer, C. Aldunate e I Solimano, pp. 227-263. Andrés Bello, Santiago.

Niemeyer, H,, G, Castillo y M. Cervellino 1991a. Estrategia del dominio Inca en el valle de Copiapó. Actas del XII Congreso Nacional de Arqueológia Chilena, pp. 333-371. Museo Regional de La Araucanía, Temuco.

Niemeyer, H., M. Cervellino y G. Castillo 1991b. Los Períodos Temprano y Medio en la cuenca del río Pulido, Provincia de Copiapó, III Región de Atacama. Actas del XI Congreso Nacional de Arqueología Chilena, pp. 1-24. Museo Nacional de Historia Natural, Sociedad Chilena de Arqueología, Santiago.

Niemeyer, H., M. Cervellino y G. Castillo 1998. Culturas Prehistóricas de Copiapó. Chile: Museo Regional de Atacama, Santiago.

Noakes, J., G. Norton, R. Culp, M. Nigham y D. Dvoracek 2006. A comparison of analytical methods for the certification of biobased products. En Advances in Liquid Scintillation Spectrometry, editado por S. Chalupnik, F. Schönhofer y J. Noakes, pp. 259-271. University of Arizona, Tucson.

Pacheco, A., P. Gómez y P. Rivas 2013. Pescadores-recolectorescazadores costeros del arcaico tardío del norte de Chile: Punta Totoralillo ( $\left.26^{\circ} 51^{\prime} \mathrm{S} ; 70^{\circ} 48^{\prime} \mathrm{W}\right)$. Actas XVIII Congreso Nacional de Arqueología Argentina, pp. 60-61. La Rioja.

Planella, M.T., F. Falabella, C. Belmar y L. Quiroz 2014. Huertos, chacras y sementeras. Plantas cultivadas y su participación en los desarrollos culturales de Chile central. Revista Española de Antropología Americana 44:495-522.

Rivas, P. 2008. Línea Base Arqueología para EIA Proyecto Minero Caserones (Ex Regalito) de Lumina Coppers, III Región. Aswakiar Consultores EIRL para Gestión Ambiental Consultores, Santiago.

Rivas, P. 2011. Plan de Manejo arqueológico proyecto Caserones de Lumina Copper S.A., III Región. Aswakiar Consultores EIRL, para Gestión Ambiental Consultores, Santiago.

Rivas, P. y J. González 2013. Informe final medidas de mitigación arqueológicas Puerto Punta Totoralillo, III Región. para Compañía Minera del Pacífico, Santiago.

Royer, A., V. Daux, F. Fourel y C. Lécuyer 2017. Carbon, nitrogen and oxygen isotope fractionation during food cooking: Implications for the interpretation of the fossil human record. American Journal of Physical Anthropology 163:759-771.

Sanhueza, L. y F. Falabella 2010. Analysis of stable isotopes: from the archaic to the horticultural communities in central Chile. Current Anthropology 51:127-136.

Santana-Sagredo, F., J.A. Lee-Thorp, R. Schulting y M. Uribe 2015. Isotopic evidence for divergent diets and mobility patterns in the Atacama Desert, northern Chile, during the Late Intermediate Period (AD 900-1450). American Journal of Physical Anthropology 156:374-387.

Schoeninger, M. y M. DeNiro 1984. Nitrogen and carbon isotopic composition of bone collagen from marine and terrestrial animals. Geochimica et Cosmochimica Acta 48:625-639.

Schwarcz, H. y M. Schoeninger 2012. Stable isotopes of carbon and nitrogen as tracers for paleo-diet reconstruction. En Handbook of Environmental Isotope Geochemistry, pp. 725742. Springer-Verlag, Berlín.

Services, S.W. 2008. Modelo numérico hidrogeológico preliminar Proyecto Caserones. https://www.e-seia.cl/archivos/ c7c_20081019.193226.pdf

Smith, E.K., W.J. Pestle, A. Clarot y F. Gallardo 2017. Modeling breastfeeding and weaning practices (BWP) on the Coast of Northern Chile's Atacama Desert during the Formative Period. The Journal of Island and Coastal Archaeology 12:558-571.

Tieszen, L. y M. Chapman 1992. Carbon and nitrogen isotopic status of the major marine and terrestrial resources in the Atacama desert of northern Chile. Presented at Actas del I Congreso Internacional de Estudios sobre Momias= 
Proceedings of the I World Congress on Mummy Studies, Santa Cruz de Tenerife.

Troncoso, A, G, Cantarutti y P. González 2016. Desarrollo histórico y variabilidad espacial de las comunidades alfareras del Norte Semiárido (ca. 300 años a.C. a 1.450 años d.C.). En Prehistoria en Chile. Desde sus Primeros Habitantes hasta los Incas, editado por F. Falabella, M. Uribe, L. Sanhueza, C. Aldunate y J. Hidalgo, pp. 319-364. Editorial Universitaria, Santiago.

Troncoso, A. y D. Pavlovic 2013. Historia, saberes y prácticas: un ensayo sobre el desarrollo de las comunidades alfareras del Norte Semiárido Chileno. Revista Chilena de Antropología 101-140.

Troncoso, R., M. Espinoza, Y. Pérez, R. Castro, M. Lorca, N. Vega, P. Feuker, C. Arévalo, E. Mercado, C. Creixell, M. Ortiz y R. Wall 2012. Evaluación Hidrogeológica de la cuenca del río Copiapó, con énfasis en la cuantificación, dinámica y calidad química de los recursos hídricos superficiales y subterráneos. SERNAGEOMIN, Santiago.

Tsutaya, T. y M. Yoneda 2013. Quantitative reconstruction of weaning ages in archaeological human populations using bone collagen nitrogen isotope ratios and approximate bayesian computation. PLOS ONE 8: e72327.

Tsutaya, T. y M. Yoneda 2015. Reconstruction of breastfeeding and weaning practices using stable isotope and trace element analyses: A review. American Journal of Physical Anthropology $156: 2-21$.

Tykot, R.H., F: Falabella, M.T. Planella, E. Aspillaga, L. Sanhueza y C. Becker 2009. Stable isotopes and archaeology in central Chile: methodological insights and interpretative problems for dietary reconstruction. International Journal of Osteoarchaeology 19:156-170.

van Klinken, G.J. 1999. Bone collagen quality indicators for palaeodietary and radiocarbon measurements. Journal of Archaeological Science 26:687-695.

Vogel, J.S., J.R. Southon, D.E. Nelson y T.A. Brown 1984. Performance of catalytically condensed carbon for use in accelerator mass spectrometry. Nuclear Instruments and Methods in Physics Research Section B: Beam Interactions with Materials and Atoms 5:289-293.

White, C., M. Spence, H. Stuart-Williams y H. Schwarcz 1998. Oxygen isotopes and the identification of geographical origins: The Valley of Oaxaca versus the Valley of Mexico. Journal of Archaeological Science 25:643-655.

Wright, L. y H. Schwarcz 1998. Stable carbon and oxygen isotopes in human tooth enamel: Identifying breastfeeding and weaning in prehistory. American Journal of Physical Anthropology 106:1-18. 
